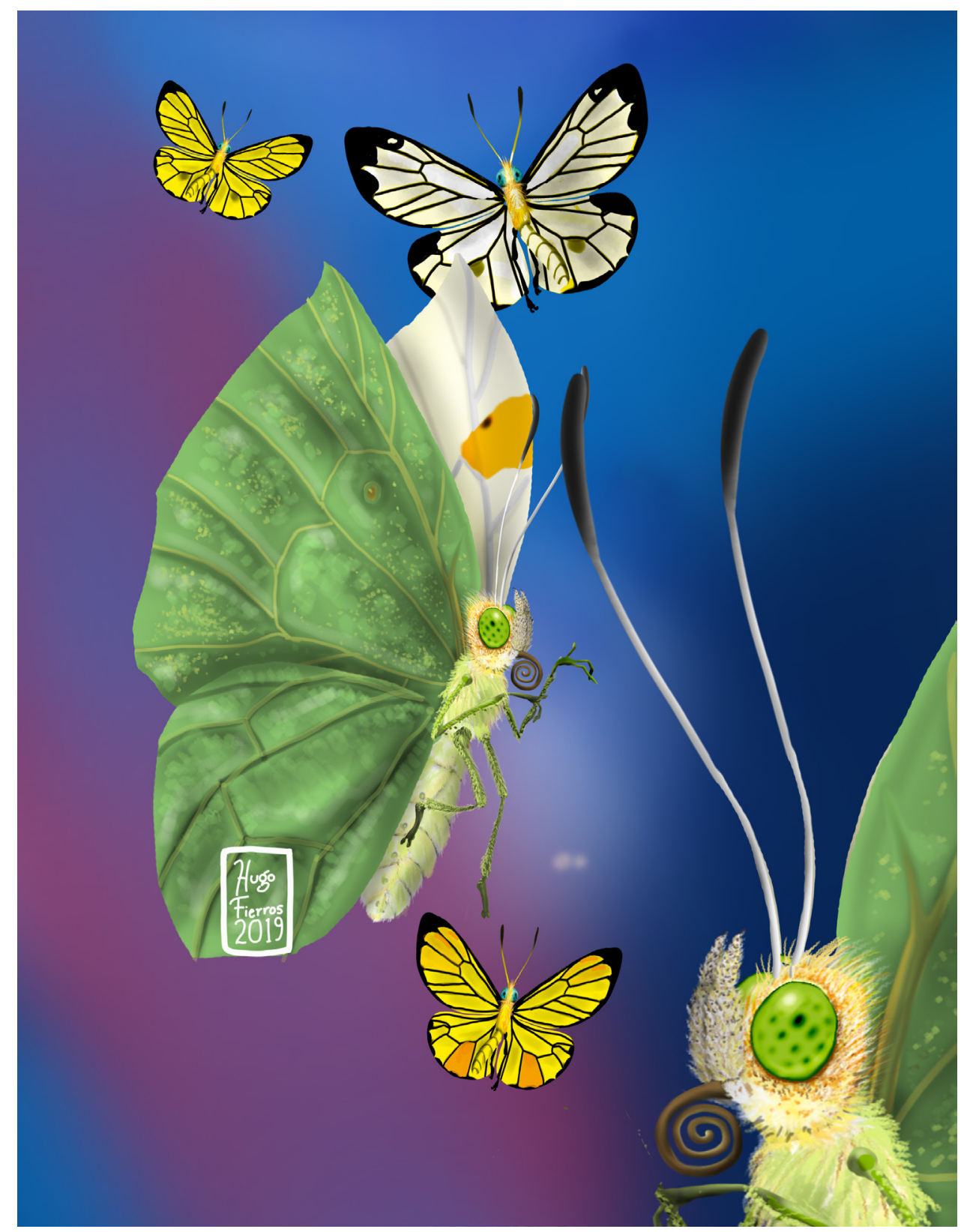

Dugesiana, Año 26, No. 2, julio 2019-diciembre 2019 (segundo semestre de 2019), es una publicación semestral, editada por la Universidad de Guadalajara, a través del Centro de Estudios en Zoología, por el Centro Universitario de Ciencias Biológicas y Agropecuarias. Camino Ramón Padilla Sánchez \# 2100, Nextipac, Zapopan, Jalisco, Tel. 37771150 ext. 33218, http://148.202.248.171/dugesiana/index.php/DUG/index, glenusmx@gmail.com. Editor responsable: José Luis Navarrete Heredia. Reserva de Derechos al Uso Exclusivo 04-2009-062310115100203, ISSN: 2007-9133, otorgados por el Instituto Nacional del Derecho de Autor. Responsable de la última actualización de este número: José Luis Navarrete Heredia, Editor y Ana Laura González-Hernández, Asistente Editorial. Fecha de la última modificación 25 de julio 2019, con un tiraje de un ejemplar.

Las opiniones expresadas por los autores no necesariamente reflejan la postura del editor de la publicación.

Queda estrictamente prohibida la reproducción total o parcial de los contenidos e imágenes de la publicación sin previa autorización de la Universidad de Guadalajara. 
Artículo

\title{
Listado ilustrado de las especies de Scarabaeinae (Coleoptera: Scarabaeidae) de la Reserva de la Biósfera de Calakmul, Campeche, México
}

\author{
Illustrated checklist of the Scarabaeinae species (Coleoptera, Scarabaeidae) from the Calakmul Bio- \\ sphere Reserve, Campeche, Mexico
}

\section{Victoria Capello $^{1^{*}}$ y Gonzalo Halffter ${ }^{2}$}

Red de Ecoetología, Instituto de Ecología, A.C., Xalapa, Veracruz, México. ${ }^{1 *}$ vicky.capello@gmail.com; ${ }_{-}^{2}$ gonzalo. halffter@inecol.mx

\begin{abstract}
RESUMEN
Se presenta un listado ilustrado de la fauna de Scarabaeinae de la Reserva de la Biósfera Calakmul (Estado de Campeche, México) elaborado con base en los resultados del trabajo de campo intensivo realizado durante la estación seca (abril-mayo) y la estación lluviosa (junio-agosto) de 2014. Los escarabajos se capturaron utilizando trampas de caída cebadas con excremento humano o carroña, y se colectaron directamente en cada sitio de estudio y sus alrededores. En total se registraron 47 especies de Scarabaeinae, pertenecientes a 16 géneros. 35 de ellas corresponden a nuevos registros para Campeche. Se presentan ilustraciones para cada especie, así como datos de distribución y notas ecológicas.

Palabras clave: Escarabajos del estiércol, Bosques tropicales, Diversidad de Especies, Selva Maya, Corredor Biológico Mesoamericano.
\end{abstract}

\begin{abstract}
An illustrated checklist of Scarabaeinae dung beetle species from the Calakmul Biosphere Reserve (State of Campeche, México) was put together with the results of intensive fieldwork carried out during the dry season (April-May) and the rainy season (June-August) of 2014. The beetles were sampled using pitfall traps baited with human excrement or carrion, and collected directly within each study site and its surroundings. A total of 47 species of Scarabaeinae, belonging to 16 genera, were recorded. 35 of them are new records for Campeche. Illustration are presented for every species, as well as distribution data and ecological notes.
\end{abstract}

Key words: Dung Beetles, Tropical Forests, Species Diversity, Selva Maya, Mesoamerican Biological Corridor.

En México está el límite septentrional de distribución de los bosques neotropicales. Con más de 723,000 ha, la Reserva de la Biósfera de Calakmul (RBC) es uno de los remanentes de bosque tropical más grande y mejor conservado de México, y una región poco estudiada. Como parte del Corredor Biológico Mesoamericano y dada su proximidad a la Reserva de la Biósfera Sian Ka'an en Quintana Roo, Calakmul es fundamental para la continuidad del paisaje de los bosques tropicales dentro de la Selva Maya, que se extiende a través de México, Guatemala y Belice. La RBC permite la conexión de la biota entre las regiones subxéricas del norte de la Península de Yucatán y las zonas de clima subhúmedo y húmedo al sur, Petén e Istmo de Tehuantepec (Díaz-Gallegos et al. 2008).

La reserva fue creada en 1989 en respuesta a las preocupaciones por el aumento de la tasa de deforestación luego de una recolonización significativa del sur de la península de Yucatán. En 1993, la RBC fue integrada al Programa sobre el Hombre y la Biósfera de la UNESCO, y recientemente, en 2014, Calakmul fue reconocida por la UNESCO como Patrimonio Mixto de la Humanidad, Cultural y Natural (Fig. 1).

Las reservas de biósfera se han establecido para promover enfoques interdisciplinarios en la gestión, la investigación y la educación para la conservación de los ecosistemas y el uso sostenible de los recursos naturales. Datos y medidas de biodiversidad confiables, dentro y fuera de las áreas protegidas, son primordiales para elaborar políticas de conservación exitosas. Ante la imposibilidad de registrar todos los seres que conforman un ecosistema, los estudios de biodiversidad se refieren a un grupo restringido de especies: el grupo focal o indicador. Los escarabajos copro-necrófagos forman parte de diversos procesos ecológicos esenciales para el funcionamiento de los ecosistemas naturales y modificados (Nichols et al. 2008). Esto sumado a la existencia de métodos de muestreo estandarizados, la disponibilidad de suficiente información sobre la biología y la taxonomía de las especies, así como la posibilidad de obtener una muestra representativa de los ensambles en tiempos acotados, son algunas de las razones 


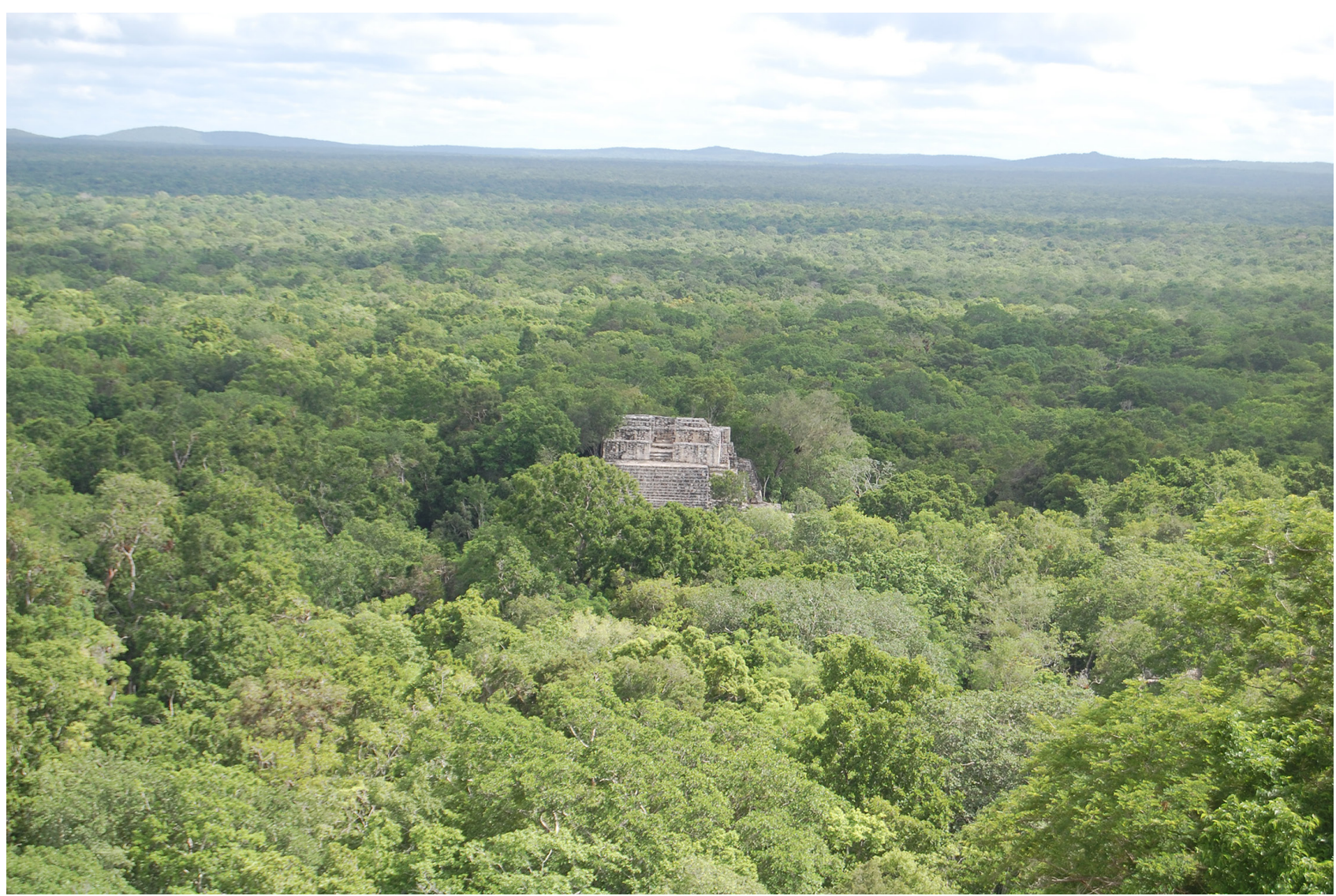

Figura 1. Estructura VII de la antigua ciudad de Calakmul rodeada de selva. Fotografía tomada desde la estructura II por Albert Maurilio Chan Dzul.

por las cuales la subfamilia Scarabaeinae (Coleoptera: Scarabaeidae) ha sido recomendada como taxón focal para el estudio de la biodiversidad en repetidas ocasiones (Halffter y Favila 1993, Halffter 1998, Spector 2006, Nichols y Gardner 2011). El estudio de este grupo a escala global, ha construido una base de datos amplia y consistente que permite comparar los patrones de diversidad entre escalas, regiones, y continentes.

En los trópicos, donde la variación térmica no es tan significativa ni las temperaturas mínimas son tan extremas, la distribución de las precipitaciones a lo largo del año influye en la dinámica de los ensambles de escarabajos (Cambefort y Hanski 1991). Por otra parte, los estudios están comenzando a reconocer y a examinar cómo se relacionan la estructura de los ensambles de mamíferos y de escarabajos. Se ha prestado especial atención a los efectos indirectos de la caza de mamíferos sobre la subfamilia Scarabaeinae en bosques tropicales (Andresen y Laurance 2007, Nichols et al. 2009, Culot et al. 2013, Feer y Boissier 2015). También se han estudiado algunos aspectos de la ecología y el comportamiento de los escarabajos en relación con monos y otros mamíferos arbóreos (Halffter y Matthews 1966, Rivera-Cervantes y Halffter 1999, Herrera et al. 2002, Vulinec et al. 2007, Jacobs et al. 2008), revelando que en los bosques tropicales no todas las especies de Scarabaeinae adquieren sus recursos a nivel del suelo. Debido a su impacto en la disponibilidad de recursos alimenticios, la distribución espacial y los patrones de actividad del ensamble de mamíferos pueden ser una fuente de heterogeneidad natural para los escarabajos.

Reconocer la no uniformidad de la naturaleza al analizar patrones de diversidad es necesario para evaluar con precisión cuánto han divergido los paisajes manejados por el hombre de su estado original y distinguir las alteraciones impulsadas por el hombre de la variación natural. Del mismo modo, existe una necesidad urgente de dar cuenta de la biodiversidad a nivel mundial; cuánto hay y cuánto se está perdiendo. El presente trabajo contribuye al conocimiento de la biodiversidad de los bosques tropicales a través del estudio de un grupo crítico: los escarabajos de la subfamilia Scarabaeinae.

\section{Importancia del área}

Uno de los propósitos más llamativos del actual Gobierno Mexicano es la rehabilitación o en su caso construcción de una vía férrea que una las ciudades del norte de la Península de Yucatán con diversos puntos de interés de la misma Península, hasta llegar a las grandes metrópolís del mundo Maya: Calakmul y Palenque. Estas dos ciudades, muy conservadas tanto en su componente arqueológico como en su entorno de selva siempre verde, son recuerdos vivos del esplendor del mundo Maya, ciudades que en distintos 
momentos gobernaron buena parte de la región.

Actualmente se llega a estos dos sitios arqueológicos por una carretera en buen estado que permite un tráfico fácil, aunque no forzosamente rápido, pero que al mismo tiempo permite un control eficiente por parte de las autoridades encargadas del patrimonio histórico y de las encargadas del patrimonio natural. Es indudable que el tren plantea un problema muy serio con la llegada masiva no solamente de turismo, sino también de tiendas de recuerdos, tiendas de comida, artículos para el turismo, entre otras. Regular el acceso a las zonas arqueológicas y evitar la destrucción que se podría provocar tanto al patrimonio cultural, como al patrimonio natural resulta un asunto primordial.

Para proteger el patrimonio natural, uno de los puntos fundamentales es tener un programa de monitoreo. Se han hecho ensayos con distintos grupos de seres vivos y los escarabajos de la subfamilia Scarabaeinae son uno de los elementos más apropiados para establecer un programa de monitoreo. Se conoce el comportamiento de la fauna de Scarabaeinae en Calakmul y en Palenque. Este conocimiento puede ser utilizado para establecer tanto planes de acción para evitar su deterioro, como planes de monitoreo a mediano y largo plazo. La protección permanente de esta riqueza excepcional, tanto cultural como natural, se convierte en una prioridad que no podemos posponer, ante los atractivos del desarrollo inmediato.

\section{MATERIALES Y MÉTODOS \\ Área de estudio}

Calakmul está ubicada en la península de Yucatán, al sudeste del estado de Campeche, en México $\left(18^{\circ} 36.72^{\prime} \mathrm{N}\right.$, $89^{\circ} 32.88^{\prime} \mathrm{W}$ ) (Fig. 2). La reserva se divide en dos zonas núcleo (una ubicada al sudeste y otra al norte, sumando $248,260 \mathrm{ha})$ y una zona de amortiguamiento (474,924 ha) (CONANP 2001, INE 1999).

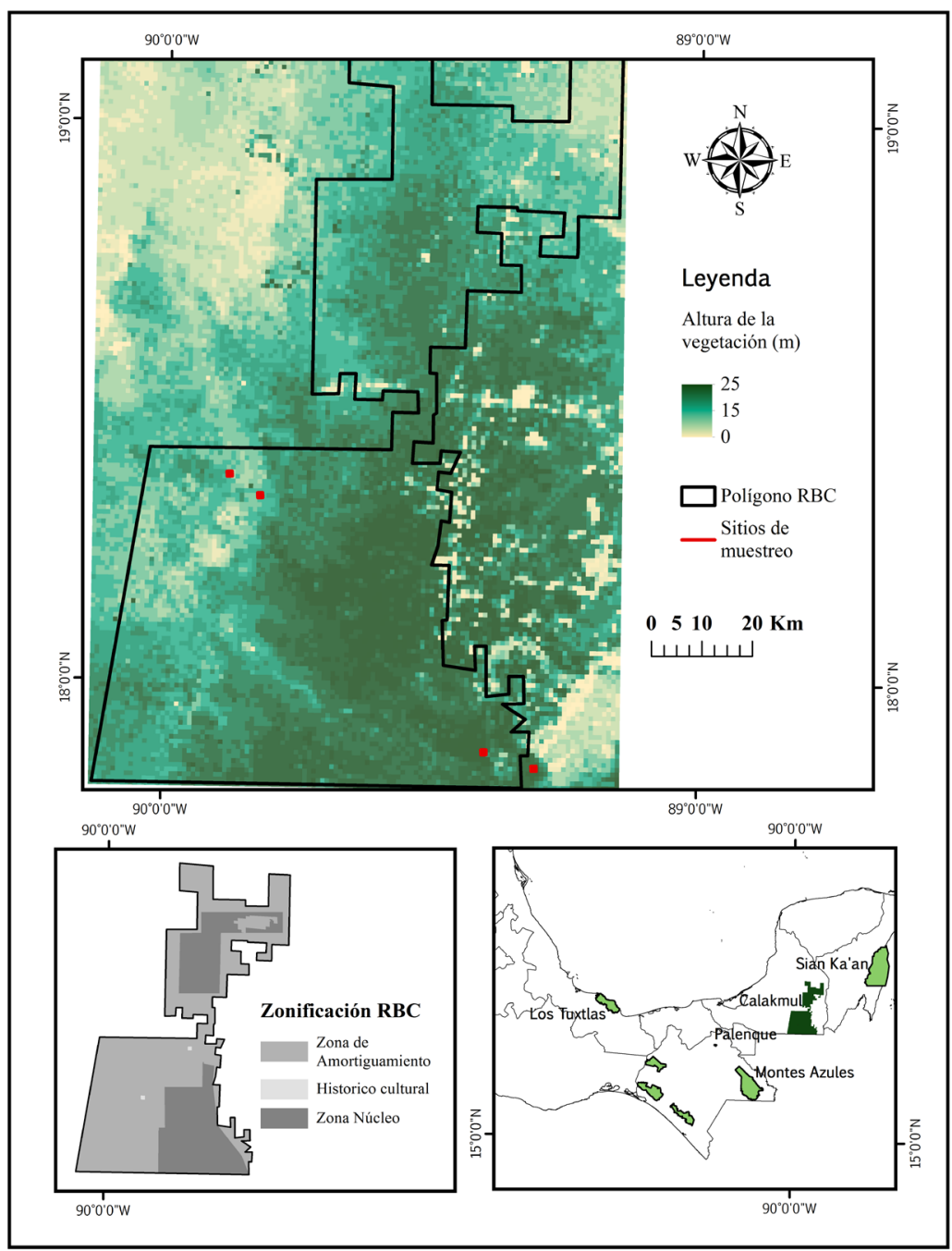

Figura 2. Área de estudio y ubicación de los sitios de muestreo dentro de la Reserva de la Biósfera Calakmul (RBC), en el sur de la Península de Yucatán, Campeche, México. Modelo de elevación digital Lidar de alta resolución (INEGI, 2009). 
El clima en la RBC es cálido subhúmedo (Aw0, Aw1, Aw2 según Köppen), con una temperatura media anual de $24.6{ }^{\circ} \mathrm{C}$ (Martínez y Galindo-Leal 2002). La estacionalidad en las precipitaciones es pronunciada; se registran menos de $50 \mathrm{~mm}$ durante el mes más seco (Marzo) y las precipitaciones varían considerablemente de un año a otro, entre 552 y 1634 $\mathrm{mm}$ anuales. Sumado a esto, existe un gradiente decreciente de precipitación del SE al NO. La altura del terreno va de los 260 a los $385 \mathrm{msnm}$, e incluye las partes más elevadas de la Península de Yucatán (García Gil et al. 2002). Estos suelos poco profundos de naturaleza kárstica, rendzinas, se caracterizan por una capa superficial de materia orgánica abundante y baja capacidad de retención de agua (García Gil et al. 2002, INEGI 2000).

El paisaje de la RBC comprende un mosaico heterogéneo de diferentes tipos de vegetación (Fig. 3). Martínez y Galindo-Leal (2002) describieron siete tipos de vegetación y hasta 27 asociaciones específicas principales, caracterizadas por la altura de los árboles, la abundancia relativa de especies arbóreas y el grado de pérdida del follaje durante la estación seca. Con base en los tipos de vegetación descriptos por Martínez y Galindo-Leal (2002) en este trabajo se estudiaron: selvas sub-perennifolias altas, medianas y bajas, selvas sub-caducifolias medianas y bajas, y bajos inundables (Cuadro 1). Esta clasificación se hizo teniendo en cuenta observaciones hechas en campo de la fisonomía y fenología de las especies dominantes, la altura y composición de la vegetación arbórea y las condiciones del suelo; así como otros estudios sobre la vegetación en el área (Tun-Dzul et al. 2008). En Calakmul, la vegetación está predominantemente influida por el grado de desarrollo del suelo, el gradiente de precipitación sureste-noroeste, las perturbaciones naturales (i.e. huracanes, sequías, incendios) y antrópicas (i.e. la influencia de la cultura maya) (García Gil et al. 2002, Martínez y Galindo-Leal 2002).

Calakmul es el hogar de alrededor de 94 especies de mamíferos, en su mayoría murciélagos (Carabias et al., 2000). Entre las especies no voladoras se encuentran: mono aullador Alouatta pigra Lawrence, 1933, mono araña Ateles geoffroyi Kuhl, 1820 (Fig. 4), hormiguero Cyclops didactylus (Linnaeus, 1758), coatí Nasua nasua (Linnaeus, 1766), mapache Procyon lotor (Linnaeus, 1758), oso hormiguero o tamandúa Tamandua mexicana (Saussure, 1860) hasta aquí todas especies de hábitos arbóreos; así como especies no arbóreas: jaguar Panthera onca (Linnaeus, 1758), puma Puma concolor (Linnaeus, 1771), pecarí labiado Tajassu pecari (Link, 1795), pecaría de collar Pecari tajacu (Linnaeus, 1758), tapir Tapirus bairdii (Gill, 1865),venado cola blanca Odocoelius virginianus (Zimmermann , 1780), temazate pardo Mazama pandora Merriam, 1901, corzuela colorada M. americana (Erxleben, 1777), tlacuachín Marmosa canescens (JA Allen, 1893), tlacuache Didelphis marsupialis Linnaeus, 1758, y zorro gris Urocyon cinereargenteus (Schreber, 1775) (Carabias et al. 2000).

Diseño de muestreo: Se llevó a cabo un muestreo de Calakmul utilizando como unidades, cuatro parcelas o cuadrantes de $1 \mathrm{~km}^{2}$ y seis tipos de vegetación diferentes (Halffter y Rös 2013). La ubicación de las trampas a nivel del suelo quedó determinada al subdividir las parcelas en 16 celdas de $250 \mathrm{~m}$ de lado y colocar cuatro trampas separadas por al menos $50 \mathrm{~m}$ (Larsen y Forsyth 2005) en el centro de cada celda (256 de trampas en total).

\section{Colecta e Identificación de escarabajos}

Los escarabajos se colectaron empleando trampas de caída cebadas con excremento humano o carroña (Fig. 5) (Morón y Terrón 1984, Larsen et al. 2006). Las trampas estuvieron activas durante 24 horas. Los escarabajos capturados se mantuvieron en etanol al $70 \%$. El muestreo se llevó a cabo durante 2014 en la mitad de la estación seca (abril-mayo) y al comienzo de la estación lluviosa (junioagosto), buscando maximizar el contraste en la vegetación y las condiciones microambientales (i.e. temperatura, humedad, porcentaje de cobertura del dosel) entre las selvas

Cuadro 1. Tipos de vegetación estudiados en Calakmul. *Altura de las especies arbóreas en metros.

\begin{abstract}
Bajos inundables
Los bajos se encontraron en áreas de menor altitud, con suelos menos compactos e inundados estacionalmente. Registraron la mayor variación en la temperatura diaria. Es el tipo de vegetación menos frecuente dentro de las áreas de estudio.

Selvas sub-perennifolias Se ubican al sur de la reserva. 25 - 50\% de las especies arbóreas pierden sus hojas en la estación seca. Las selvas sub-perennifolias registraron menor variación diaria en la temperatura y mayor precipitación anual que las selvas sub-caducifolias. Las selvas sub-perennifolias difieren respecto de la fisonomía de la vegetación, así como en su distribución en las áreas examinadas.

Medianas $15 \mathrm{~m}<*<25 \mathrm{~m}$

Bajas $*<15 \mathrm{~m}$

Selvas sub-caducifolias

Estas selvas se encuentran hacia el centro de la reserva, donde el suelo está menos desarrollado, la variación diaria de la temperatura es mayor y las precipitaciones son menos abundantes.

Medianas $15 \mathrm{~m}<*<25 \mathrm{~m}$ Durante al menos dos meses en el verano, más del 75\% las especies arbóreas pierde sus hojas, aunque el elemento caducifolio puede variar en diferentes años dependiendo de la duración Bajas * $<15 \mathrm{~m}$ respecto a la fisonomía de la vegetación y su distribución en la reserva.
\end{abstract}




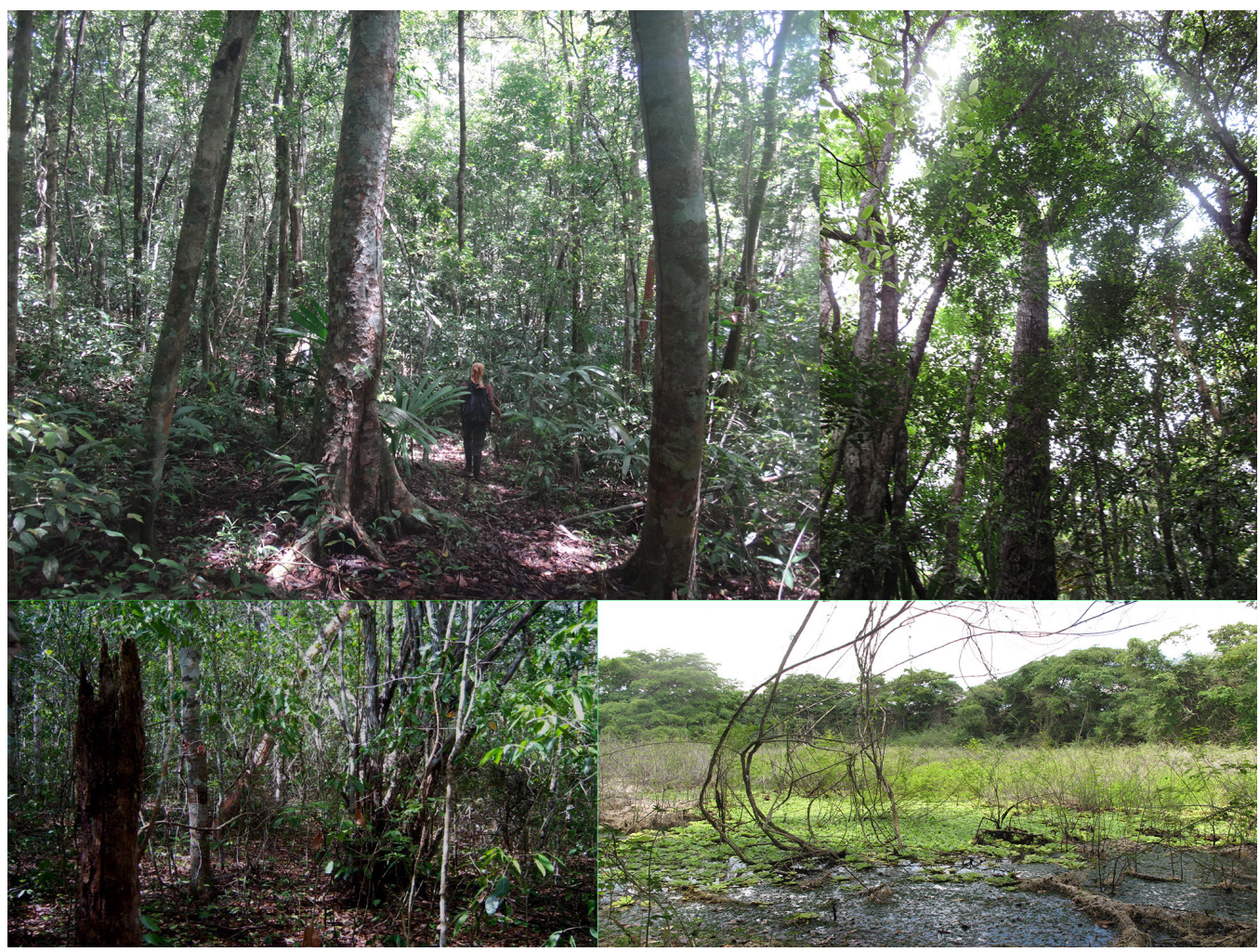

Figura 3. Algunos de los componentes del mosaico de tipos de vegetación en Calakmul.

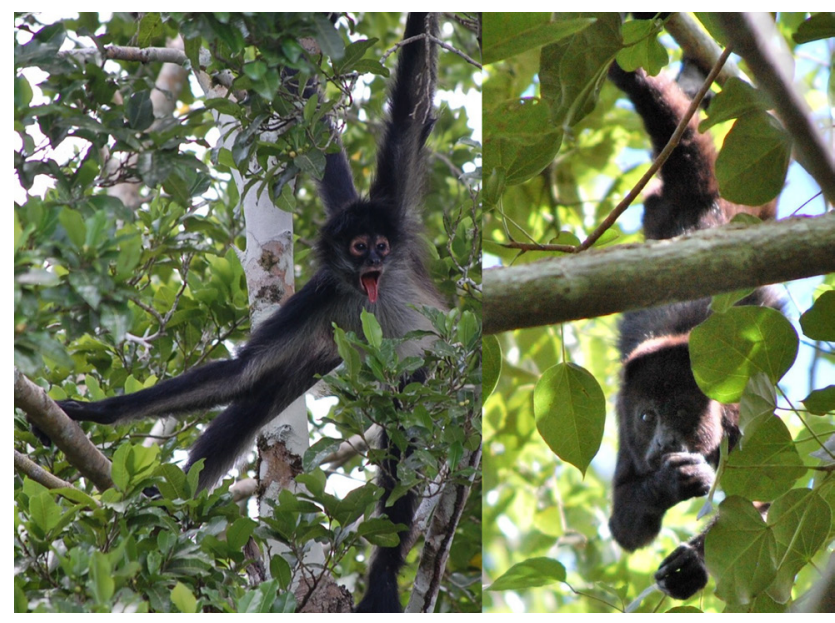

Figura 4. Mono araña Ateles geoffroyi (izquierda) y mono aullador Alouatta pigra (derecha) en el dosel de las selvas sub-perennifolias de Calakmul. Fotografías tomadas por Albert Maurilio Chan Dzul.

sub-perennifolias y las selvas sub-caducifolias. Todos los sitios fueron muestreadas durante la temporada de lluvias y solo la mitad durante la estación seca. Los permisos necesarios para este trabajo se obtuvieron de los ejidos Arroyo Negro, Conhuás y Dos Lagunas Sur; así como de la Comisión Nacional de Áreas Naturales Protegidas (CONANP), y de la Secretaría de Medio Ambiente y Recursos Naturales (SEMARNAT).

Durante el trabajo de campo, además del muestreo sistemático empleando trampas de caída (colectas

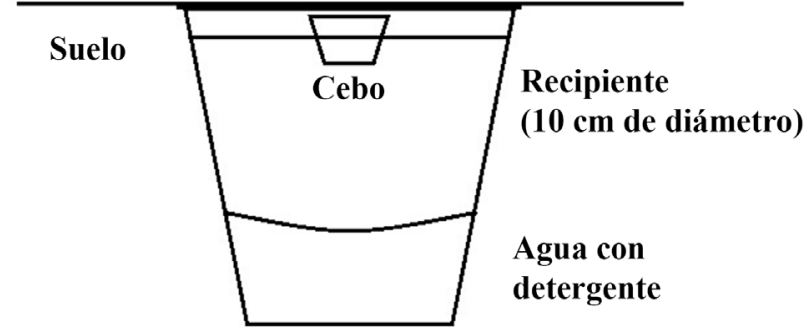

Figura 5. Diagrama de una trampa de caída con cebo ya instalada al ras del suelo.

indirectas), se inspeccionaron todas las excretas (frescas), las frutas en descomposición y restos de vertebrados e invertebrados encontrados en el camino (colectas directas); se anotaron las coordenadas geográficas, fecha y hora, tipo de vegetación y observaciones. Las excretas fueron identificadas con ayuda de los guías locales, Diego Meneses del ejido Dos Lagunas Sur y Mauro Barrientos del ejido Conhuás. La ubicación de las trampas de caída y las observaciones se registraron con un GPS Garmin de mano (GPSMAP ${ }^{\circledR}$ 62s, Garmin, datum WGS84). Incluir 
en el muestreo formas de colecta directas e indirectas, permite una visión más amplia de la diversidad presente y proporciona información acerca de la biología de las especies en su ambiente natural.

Para la identificación de las especies se consultaron: i) Revisiones taxonómicas, monografías y claves de identificación (Halffter 1961, Howden 1965, RiveraCervantes y Halffter 1999, Arnaud 2002, Kohlmann y Solís 2006, Delgado et al. 2006, Delgado y Kohlmann 2007, Pulido Herrera et al. 2007, Vaz-De-Mello 2008, Génier 2009, Edmonds y Zidek 2010, González-Alvarado y Vaz-de-Mello 2014, Silva et al. 2015), ii) colecciones del Instituto de Ecología AC, Xalapa (IEXA), Halffter y Escobar Hernández; y iii) especialistas (Gonzalo Halffter, Fernando Escobar Hernández, Mario Zunino y Leonardo Delgado). Ejemplares de referencia se depositaron en las colecciones entomológicas del Instituto de Ecología A.C. (IEXA), en la colección entomológica Hope del Museo de Historia Natural de la Universidad de Oxford (OUMNH) y en la del Dr. Gonzalo Halffter. En los datos de distribución, el estado de Campeche aparece en negritas (Campeche) cuando se registra por primera vez para el estado.

Las imágenes incluidas en este trabajo fueron tomadas usando una cámara Canon T2i con una lente Canon de 100 mm Macro y un set de tubos de extensión Kenko; y con un microscopio multifocal Leica-Z16AP0A. También se incluyen datos de distribución y notas ecológicas sobre las especies.

\section{RESULTADOS}

En este estudio se colectaron 22,753 individuos distribuidos en 47 especies de Scarabaeinae pertenecientes a 16 géneros en la Reserva de la Biósfera Calakmul. Cinco de estos géneros eran apreciablemente ricos en especies: Onthophagus (10 especies), Canthon (6), Canthidium (5), Deltochilum (5) y Eurysternus (5). De las 47 especies encontradas, 35 especies corresponden a nuevos registros para el Estado de Campeche (especies indicadas al escribir Campeche en negrita).

Desde un enfoquebiogeográfico, la fauna de Scarabaeinae en Calakmul presentó un origen predominantemente neotropical con algunos elementos de origen Septentrional o del Viejo Mundo.

Las fotografías (Figuras 6-52) ilustran las 47 especies encontradas dentro de la reserva. Para las especies que presentan dimorfismo sexual evidente se incluyen fotografías de hembra y macho.

\section{Scarabaeinae de Calakmul}

Género Canthon Hoffmannsegg, 1817

Subgénero Canthon Hoffmannsegg, 1817

Canthon (Canthon) cyanellus cyanellus LeConte, 1860

(Figura 6)

Observaciones: Canthon cyanellus fue la especie registrada con mayor frecuencia. Todas las observaciones fuera de las trampas revelan hábitos necrófagos. Entre los ejemplares colectados en Calakmul se distingue en forma evidente dos grupos de tamaño.

Registros de campo: Los adultos se colectaron tanto en la estación seca como lluviosa. Con frecuencia en cadáveres de zorro gris Urocyon cinereargenteus (Schreber, 1775) (Carnivora: Canidae), lagarto tolok verde o Laemanctus serratus Cope, 1864 (Squamata: Corytophanidae), Bufo valliceps (Wiegmann, 1833) (Anura: Bufonidae), Enema endymion Chevrolat, 1843 (Coleoptera: Scarabaeidae: Dynastinae), así como también en cáscaras de huevos de pavo ocelado Meleagris ocellata Cuvier, 1820 (Galliformes: Phasianidae) y en una crisálida de polilla vacía (Lepidoptera).

Distribución en México: Campeche, Chiapas, Guerrero, Hidalgo, Jalisco, Morelos, Nayarit, Nuevo León, Oaxaca, Puebla, Quintana Roo, San Luis Potosí, Tabasco, Tamaulipas, Veracruz, Yucatán (Halffter 2003).

Distribución fuera de México: Belice, Colombia, Costa Rica, Guatemala, Nicaragua, Panamá, Venezuela, Estados Unidos (Cano 1998b, Halffter 1961, SNIBCONABIO 2016).

Canthon (Canthon) indigaceus chiapas Robinson, 1948 (Figura 7)

Observaciones: A lo largo de todo el estudio sólo se ha colectado un individuo de esta especie, en selva baja subcaducifolia durante la estación seca, en una trampa cebada con excremento humano.

Distribución en México: Campeche, Chiapas, Hidalgo, Veracruz (Halffter 1961, SNIB-CONABIO 2016).

\section{Subgénero Glaphyrocanthon Martínez, 1948 \\ Canthon (Glaphyrocanthon) euryscelis Bates, 1887} (Figura 8)

Observaciones: Durante la estación seca $C$. (Gl.) euryscelis era la primera especie en llegar a las trampas instaladas con excremento humano. Algunos individuos comenzaban a hacer bolas en la trampa. Especie relativamente muy abundante y muy activa.

Registros de campo: Los adultos se colectaron durante ambas estaciones y en ambos tipos de selvas. Durante la estación seca no sólo se colectaron en las trampas, si no también en el cadáver de un lagarto Tolok verde o Laemanctus serratus, y en excreta de tapir Tapirus bairdii (Perissodactyla: Tapiridae) al segundo día de revisarla.

Distribución en México: Campeche, Chiapas, Guerrero, Oaxaca, Quintana Roo, Tabasco, Veracruz, Yucatán (Halffter 2003, Alvarado et al. 2018, SNIBCONABIO 2016).

Distribución fuera de México: Belice, Costa Rica, Guatemala, Honduras, Nicaragua, Panamá (Halffter 2003, GBIF 2018). 
Canthon (Glaphyrocanthon) femoralis femoralis

(Chevrolat, 1834)

(Figura 9)

Observaciones: La especie fue capturada en solo uno de los sitios de estudio en selvas sub-perennifolias del sur de la reserva, durante ambas estaciones y utilizando excremento humano como cebo.

Distribución en México: Campeche, Chiapas, Colima, Guerrero, Jalisco, México, Michoacán, Nayarit, Oaxaca, Puebla, San Luis Potosí, Sinaloa, Tabasco, Tamaulipas, Veracruz (Rivera-Cervantes y Halffter 1999, SNIBCONABIO 2016).

Distribución fuera de México: Belice, Costa Rica, El Salvador, Guatemala, Honduras, Nicaragua, Panamá (Cano 1998b, Rivera-Cervantes y Halffter 1999, Halffter 2003).

Canthon (Glaphyrocanthon) leechi (Martínez, Halffter y Halffter, 1969)

(Figura 10)

Observaciones: Canthon (Gl.) leechi se colectó con mayor frecuencia en selvas sub-caducifolias durante ambas estaciones, utilizando trampas de caída cebadas tanto con excremento como con carroña.

Distribución en México: Campeche, Chiapas, Guanajuato, Guerrero, Jalisco, México, Michoacán, Morelos, Oaxaca, Puebla, Querétaro, Quintana Roo, Veracruz, Yucatán (Halffter 2003, SNIB-CONABIO 2016).

Distribución fuera de México: Costa Rica, Guatemala (Rivera-Cervantes y Halffter 1999).

\section{Canthon (Glaphyrocanthon) subhyalinus subhyalinus Harold, 1867 \\ (Figura 11)}

Observaciones: Se colectó con más frecuencia al utilizar excremento como cebo en selvas sub-perennifolias durante la temporada de lluvias. Sólo un individuo fue capturado en las selvas sub-caducifolias.

En Calakmul existe variación en la coloración de los élitros de C. (Gl.) subhyalinus. En los individuos examinados, los élitros no son translúcidos como en el patrón típico, si no que presentan reflejos metálicos variables. RiveraCervantes y Halffter (1999) mencionan que en México $C$. (Gl.) subhyalinus exhibe variación en la coloración. Para otros lugares donde se ha colectado la especie (Montes Azules, Boca de Chajul, Palenque, Los Tuxtlas, Laguna Lachua) no se ha mencionado una coloración similar a la que se encuentra en Calakmul.

Distribución en México: Campeche, Chiapas, Guerrero, Quintana Roo, Veracruz (Halffter 2003, SNIBCONABIO 2016).

Distribución fuera de México: Bolivia, Colombia, Costa Rica, Ecuador, Guatemala, Guyana Francesa, Panamá, Perú (Halffter 2003).
Género Deltochilum Eschscholtz, 1822

Deltochilum (Aganhyboma) acropyge Bates, 1887

(Figura 12)

Sinonimias: Deltochilum (Deltochilum) valgum var. acropyge Paulian, 1938

Deltochilum (Deltohyboma) valgum acropyge Howden, 1966

Deltochilum valgum acropyge: Howden y Young, 1981

Deltochilum (Aganhyboma) acropyge. Nueva ubicación subgenérica y Nuevo status. Silva et al. 2015.

Observaciones: Sólo un individuo fue capturado en una trampa cebada con excremento en las selvas subperennifolias del sur, durante la estación seca. Estudios previos en la Selva Maya asocian la "aparente rareza" de $D$. acropyge en trampas con excremento a su especialización en la depredación de diplópodos (Cano 1998a).

Distribución en México: Campeche, Chiapas, Yucatán (Halffter 2003, Alvarado et al. 2018).

Distribución fuera de México: Belice, Costa Rica, Guatemala, Panamá (Cano 1998a, Silva et al. 2015).

\section{Deltochilum (Deltochilum) scabriusculum scabriusculum Bates, 1887}

(Figura 13a)

Registros de campo: Los adultos se colectaron durante ambas estaciones y en ambos tipos de selvas. Durante la estación lluviosa no sólo se colectaron en las trampas, también se observó cómo un individuo cortaba una bola de la carne de una serpiente (Crotalus sp. (Squamata: Viperidae)) muerta, para luego rodarla (Figura 13b); y al revisar una excreta de carnívoro se encontró un individuo el primer día, y cuatro al día siguiente.

Distribución en México: Campeche, Chiapas, Guerrero, Hidalgo, Jalisco, Morelos, Nayarit, Nuevo León, Oaxaca, Puebla, Querétaro, Quintana Roo, San Luis Potosí, Sinaloa, Sonora, Tamaulipas, Veracruz, Yucatán (Génier 2012, SNIB-CONABIO 2016).

Distribución fuera de México: Belice, Costa Rica, El Salvador, Guatemala, Nicaragua, Estados Unidos (Cano 1998a, Génier 2012).

\section{Deltochilum (Deltohyboma) pseudoparile Paulian, 1938} (Figura 14)

Observaciones: $D$. pseudoparile se colectó durante ambas estaciones, sólo en selvas sub-perennifolias, en trampas cebadas con excremento o carroña.

Distribución en México: Campeche, Chiapas, Oaxaca, Quintana Roo, Tabasco, Veracruz (Halffter 2003, Navarrete y Halffter 2008).

Distribución fuera de México: Belice, Colombia, Costa Rica, Guatemala, Panamá (Cano 1998a, Latha et al. 2016, GBIF 2018). 


\section{Deltochilum (Hybomidium) lobipes Bates, 1887}

(Figura 15a)

Registros de campo: Los adultos se colectaron durante ambas estaciones y en ambos tipos de selvas. Durante la estación lluviosa no sólo se colectaron en las trampas, también se observó cómo

un individuo cortaba la carne de una serpiente (Crotalus $s p$. (Squamata: Viperidae)) muerta (Figura 15b).

Distribución en México: Campeche, Chiapas, Oaxaca, Quintana Roo, Tamaulipas, Veracruz, Yucatán (GonzálezAlvarado y Vaz-de-Mello 2014, Alvarado et al. 2018)

Distribución fuera de México: Belice, Costa Rica, El Salvador, Guatemala, Honduras, Nicaragua (GonzálezAlvarado y Vaz-de-Mello 2014).

Deltochilum (Hybomidium) carrilloi González-Alvarado y Vaz-de-Mello, 2014

(Figura 16)

Sinonimias: Deltochilum densepunctatum Balthasar, 1939

Deltochilum (Hybomidium) gibbosum sublaeve (Howden, 1966)

Deltochilum (Hybomidium) carrilloi GonzálezAlvarado y Vaz-de-Mello, 2014

Observaciones: $D$. carrilloi se distribuye ampliamente en las selvas sub-perennifolias y sub-caducifolias de Calakmul durante ambas estaciones.

Distribución en México: Campeche, Chiapas, Guerrero, Jalisco, Morelos, Oaxaca, Quintana Roo, Veracruz (González-Alvarado y Vaz-de-Mello 2014).

Distribución fuera de México: Belice, Guatemala, Nicaragua (González-Alvarado y Vaz-de-Mello 2014).

Género Megathoposoma Balthasar, 1939

Megathoposoma candezei (Harold, 1863)

(Figura 17)

Observaciones: $M$. candezei se registró asociada con sólo en selvas sub-perennifolias durante la época de lluvias.

Registros de campo: Durante la estación seca no sólo se colectaron en las trampas, también se encontró un escarabajo en una excreta de carnívoro.

Distribución en México: Campeche, Chiapas, Yucatán (Navarrete y Halffter 2008, Alvarado et al. 2018, Halffter 2003)

Distribución fuera de México: Costa Rica, Guatemala, Nicaragua, Panamá (Cano 1998b, Halffter 2003, Solís y Kohlmann 2012, GBIF 2018).

Género Pseudocanthon Bates, 1887

Pseudocanthon perplexus (LeConte, 1847)

(Figura 18)

Observaciones: Esta especie fue registrada en selvas sub-caducifolias utilizando trampas con excremento como cebo.

Distribución en México: Campeche, Chiapas, Guerrero, Jalisco, Morelos, Tabasco, Veracruz, Yucatán
(Alvarado et al. 2018, Halffter 2003)

Distribución fuera de México: Argentina, Bahamas, Brasil, Colombia, Costa Rica, El Salvador, Guatemala, Honduras, Nicaragua, Panamá, Estados Unidos, Venezuela (Cano 1998b, Padilla-Gill y Halffter 2007, Solís y Kohlmann 2012)

Género Sisyphus Latreille, 1807

Sisyphus mexicanus Harold, 1863

(Figura 19)

Observaciones: $S$. mexicanus se registró en trampas cebadas con excremento durante la temporada de lluvias.

Distribución en México: Campeche, Oaxaca, Quintana Roo, Tamaulipas, Veracruz, Yucatán (Alvarado et al. 2018, Morón 2003, SNIB-CONABIO 2016)

Distribución fuera de México: Costa Rica, Guatemala, Nicaragua (Cano 1998b, GBIF 2018).

Género Eurysternus Dalman, 1824

Eurysternus angustulus Harold, 1869*

(Figura 20)

Observaciones: E. angustulus solo fue capturada en trampas cebadas con excremento.

Distribución en México: Campeche, Chiapas, Oaxaca, Tabasco, Veracruz, Yucatán (Génier 2009, SNIBCONABIO 2016)

Distribución fuera de México: Belice, Guatemala, Panamá (Génier 2009).

\section{Eurysternus caribaeus (Herbst, 1789)}

(Figura 21)

Registros de campo: Los adultos se colectaron durante ambas estaciones y con ambos tipos de cebos en las selvas sub-perennifolias. Durante la estación lluviosa no sólo se colectaron en las trampas, también se encontraron varios individuos en excremento de tapir Tapirus bairdii fresco.

Distribución en México: Campeche, Chiapas, Guerrero, Oaxaca, Quintana Roo, Tabasco, Veracruz (Génier 2009, SNIB-CONABIO 2016).

Distribución fuera de México: Argentina, Belice, Bolivia, Brasil, Colombia, Costa Rica, Ecuador, Guatemala, Guyana, Guyana Francesa, Honduras, Nicaragua, Panamá, Paraguay, Perú, Surinam, Trinidad y Tobago, Venezuela (Génier 2009).

Eurysternus foedus Guérin-Méneville 1830 (Figura 22)

Observaciones: E. foedus sólo se colectó en selvas sub-perennifolias durante la estación seca, asociado con excremento.

Registros de campo: Los adultos no sólo se encontraron en trampas cebadas con excremento, también se colectaron varios individuos en excremento de tapir Tapirus bairdii fresco.

Distribución en México: Campeche, Chiapas, Guerrero, Veracruz (Génier 2009). 
Distribución fuera de México: Belice, Bolivia, Brasil, Colombia, Costa Rica, Ecuador, Guatemala, Guayana Francesa, Nicaragua, Panamá, Perú, Venezuela (Génier 2009).

\section{Eurysternus magnus Castelnau, 1840} (Figura 23)

Observaciones: E. magnus sólo fue capturada en selvas sub-caducifolias empleando trampas cebadas con excremento.

Registros de campo: Los adultos no sólo se encontraron en trampas cebadas con excremento, también se colectaron varios individuos en excremento de tapir Tapirus bairdii fresco.

Distribución en México: Campeche, Chiapas, Colima, Jalisco, Guerrero, Hidalgo, Nayarit, Nuevo León, Oaxaca, Puebla, Querétaro, Quintana Roo, San Luis Potosí, Tabasco, Tamaulipas, Veracruz, Yucatán, Zacatecas (Génier 2009, Morón 2003, SNIB-CONABIO 2016).

Distribución fuera de México: Belice, Costa Rica, El Salvador, Guatemala, Honduras, Nicaragua, Panamá (Génier 2009).

\section{Eurysternus mexicanus Harold, 1869}

(Figura 24)

Observaciones: Esta especie se colectó tanto en selvas sub-perennifolias como en selvas sub-caducifolias, aunque sólo durante la época de lluvias en trampas cebadas con excremento.

Distribución en México: Campeche, Chiapas, Hidalgo, Oaxaca, Querétaro, Quintana Roo, San Luis Potosí, Tabasco, Tamaulipas, Veracruz, Yucatán (Alvarado et al. 2018, Génier 2009, Morón 2003).

Distribución fuera de México: Belice, Colombia, Costa Rica, Guatemala, Guyana, Honduras, Nicaragua, Panamá, Trinidad y Tobago, Venezuela (Génier 2009).

\section{Género Ateuchus Weber, 1801 \\ Ateuchus chrysopyge (Bates, 1887) \\ (Figura 25)}

Observaciones: $A$. chrysopyge se registró en trampas cebadas con excremento cólocadas en selvas subperennifolias, durante ambas estaciones, Se colectaron tres individuos durante la estación seca y un individuo durante la época de lluvias.

Distribución en México: Campeche, Chiapas (Kohlmann 2000, Kohlmann y Vaz-de-Mello 2018).

Distribución fuera de México: Belice, El Salvador, Guatemala, Honduras (Kohlmann 2000, Kohlmann y Vazde-Mello 2018).

Género Bdelyropsis Pereira, Vulcano y Martínez, 1960 Bdelyropsis bowditchi (Paulian, 1939)

(Figura 26)

Observaciones: Especie capturada durante ambas estaciones, en los meses de mayo, junio y julio, y con ambos cebos (estiércol y carroña), aunque sólo en selvas sub-perennifolias medianas y altas.

Distribución en México: Campeche, Chiapas (Kohlmann 2003).

Distribución fuera de México: Belice, Guatemala, Honduras (Kohlmann 2003).

Género Martinezidium Vaz-de-Mello, 2008

Martinezidium maya (Vaz-de-Mello y Halffter y Halffter, 2004)

(Figura 27)

Sinonimias: Pedaridium maya: Vaz-de-Mello, Halffter y Halffter, 2004

Martinezidium maya (Vaz-de-Mello, Halffter y Halffter, 2004), nueva combinación: Vaz-de-Mello, 2008.

Observaciones: Esta especie fue capturada en selvas sub-perennifolias y sub-caducifolias, durante ambas estaciones y empleando trampas con ambos tipos de cebo. Sin embargo, se colectaron con mayor frecuencia durante la estación lluviosa, en trampas cebadas con excremento.

Distribución en México: Campeche, Chiapas, Quintana Roo, Veracruz, Yucatán (Deloya y Peraza-Flores 2005, Vaz-de-Mello, Halffter y Halffter 2004).

Distribución fuera de México: Guatemala (Vaz-deMello 2008).

Género Uroxys Westwood, 1842

Uroxys chichanich Delgado y Kohlmann, 2007

(Figura 28)

Observaciones: Esta especie sólo fue colectada durante la temporada de lluvias (junio-julio) en trampas cebadas con excremento colocadas tanto en selvas sub-perennifolias como sub-caducifolias.

Distribución en México: Campeche, Yucatán (Delgado y Kohlmann, 2007).

\section{Uroxys deavilai Delgado y Kohlmann, 2007 (Figura 29)}

Observaciones: $U$. deavilai se colectó durante ambas estaciones en trampas de caída cebadas con carroña y excremento, en selvas sub-perennifolias y sub-caducifolias.

Distribución en México: Campeche, Chiapas, Guerrero, Jalisco, Michoacán, Nuevo León, Oaxaca, Quintana Roo, San Luis Potosí, Tamaulipas, Veracruz, Yucatán (Delgado y Kohlmann 2007, SNIB-CONABIO 2016).

Distribución fuera de México: Costa Rica, Nicaragua (Delgado y Kohlmann 2007).

\section{Uroxys microcularis Howden y Young, 1981}

(Figura 30)

Observaciones: Esta especie fue colectada durante ambas estaciones, tanto en selvas sub-perennifolias como sub-caducifolias, empleando trampas cebadas excremento y carroña.

Distribución en México: Campeche, Chiapas, 
Guerrero, Hidalgo, Puebla, Quintana Roo, Tamaulipas, Veracruz, Yucatán (Delgado y Kohlmann 2007, SNIBCONABIO 2016).

Distribución fuera de México: Colombia, Costa Rica, Guatemala, Panamá (Delgado y Kohlmann 2007).

\section{Uroxys micros Bates, 1887}

(Figura 31)

Observaciones: $U$ micros fue capturada en selvas subperennifolias y sub-caducifolias durante ambas estaciones, trabajando con trampas cebadas con excremento y carroña. No obstante, su abundancia fue mucho mayor al usar excremento como cebo.

Distribución en México: Campeche, Chiapas, Guerrero, Jalisco, Estado de México, Morelos, Oaxaca, Quintana Roo, Veracruz, Yucatán (Delgado y Kohlmann 2007, SNIB-CONABIO 2016).

Distribución fuera de México: Colombia, Costa Rica, Guatemala, Honduras, Nicaragua, Panamá (Delgado y Kohlmann 2007).

Género Canthidium Erichson, 1847

Subgénero Canthidium Erichson, 1847

Canthidium (Canthidium) ardens Bates, 1887

(Figura 32)

Sinonimia: Canthidium rhodopus Bates, 1887.

Canthidium ardens mutatum Bates, 1887.

Transferido al subgénero Canthidium por Cupello, 2018.

Observaciones: $C$. ardens sólo fue capturado durante la época de lluvias (junio-julio), en las selvas medianas sub-perennifolias del sur de la reserva, en trampas con excremento como cebo.

Distribución en México: Campeche, Chiapas, Oaxaca, Veracruz (Kohlmann y Solís 2006, SNIB-CONABIO 2016).

Distribución fuera de México: Costa Rica, Guatemala, Honduras, Nicaragua, Panamá (Kohlmann y Solís 2006).

\section{Canthidium (Canthidium) moroni Kohlmann y Solís,} 2006

(Figura 33)

Sinonimia: Kohlmann, 2003 (incluido como parte de vespertinum); Solís y Kohlmann, 2004 (incluido como parte de vespertinum). (Kohlmann y Solís 2006)

Transferido al subgénero Canthidium por Cupello, 2018.

Observaciones: Esta especie se colectó durante ambas estaciones en trampas de caída con excremento como cebo, en selvas sub-perennifolias bajas y medianas.

Distribución en México: Campeche, Chiapas (Kohlmann y Solís 2006).

Distribución fuera de México: Guatemala, Honduras (Kohlmann y Solís 2006).
Canthidium (Canthidium) pseudoperceptible Kohlmann y Solís, 2006

(Figura 34)

Sinonimias: Canthidium perceptible Howden y Young, 1981

Favila y Dávila, 1997 (como aff. perceptibile); Kohlmann, 2003 (como perceptibile)

Canthidium pseudoperceptible Kohlmann y Solís, 2006

Transferido al subgénero Canthidium por Cupello, 2018.

Observaciones: Los individuos de esta especie sólo fueron capturados durante la época de lluvias (junio-julio), en las selvas medianas sub-perennifolias del sur de la reserva y utilizando trampas de caída con excremento como cebo.

Distribución en México: Campeche, Chiapas, Veracruz (Kohlmann y Solís 2006).

Distribución fuera de México: Belice, El Salvador, Guatemala (Kohlmann y Solís 2006, Cupello 2018).

Canthidium (Canthidium) pseudopuncticolle Solís y Kohlmann, 2004

(Figura 35)

Sinonimias: Canthidium pseudopuncticolle Solís y Kohlmann, 2004.

Transferido al subgénero Canthidium por Cupello, 2018.

Observaciones: Esta especie se colectó durante ambas estaciones (seca y lluviosa), con ambos cebos (estiércol y carroña), en selvas sub-perennifolias y sub-caducifolias, aunque no en todos nuestros sitios de estudio.

Distribución en México: Campeche, Chiapas, Oaxaca, Quintana Roo, San Luis Potosí, Tamaulipas, Veracruz, Yucatán (Kohlmann y Solís 2006).

Distribución fuera de México: Belice, Costa Rica, Estados Unidos, Guatemala (Kohlmann y Solís 2006).

Subgénero Neocanthidium Martínez et al., 1964

Nuevo status y revalidado por Cupello, 2018.

Canthidium (Neocanthidium) centrale Boucomont, 1928 (Figura 36)

Sinonimias: Neocanthidium martinezi Edmonds y Halffter, 1978.

Observaciones: Esta especie se recolectó en trampas con excremento como cebo, principalmente en selvas subperennifolias medianas y altas durante las estaciones seca y lluviosa. Solo se colectó un individuo en las selvas subcaducifolias (bajas) y esto fue durante la estación seca.

Distribución en México: Campeche, Chiapas, Oaxaca, Quintana Roo, Veracruz (Kohlmann 2003).

Distribución fuera de México: Colombia, Costa Rica, Guatemala, Honduras, Nicaragua, Panamá (Kohlmann 2003).

Género Copris Geoffroy, 1762

Copris incertus Say, 1835

(Figura 37)

Observaciones: Los individuos fueron capturados solo 
en selvas sub-caducifolias, durante ambas estaciones y en trampas con ambos tipos de cebo. Aún así, se colectaron con mayor frecuencia durante la estación seca.

Registros de campo: Los adultos no sólo se encontraron en trampas con cebo, durante la época seca se encontró un individuo ya enterrado y con excremento, debajo de una excreta de venado cola blanca Odocoileus virginianus (Artiodactyla: Cervidae).

Distribución en México: Campeche, Chiapas, Estado de México, Hidalgo, Jalisco, Michoacán, Oaxaca, Puebla, Quintana Roo, San Luis Potosí, Tamaulipas, Veracruz, Yucatán (Kohlmann 2003, SNIB-CONABIO 2016).

Distribución fuera de México: Belice, Colombia, Costa Rica, Ecuador, El Salvador, Guatemala, Honduras, Nicaragua, Panamá, Perú (GBIF 2018).

\section{Copris laeviceps Harold, 1869}

(Figura 38)

Observaciones: $C$. laeviceps se distribuye ampliamente en nuestros sitios de estudio, sin importar el cebo ni la estación. No obstante, se colectó con mayor frecuencia en selvas sub-perennifolias al trabajar con trampas cebadas con excremento.

Distribución en México: Campeche, Chiapas, DF (Morón 2003), Oaxaca, Quintana Roo Veracruz, Yucatán (Kohlmann 2003, Alvarado et al. 2018, SNIB-CONABIO 2016).

Distribución fuera de México: Belice, Colombia, Costa Rica, Guatemala, Honduras, Nicaragua (Cano 1998b, GBIF 2018).

Género Dichotomius Hope, 1838

Dichotomius amplicollis (Harold, 1869) (Figura 39)

Observaciones: $D$. amplicollis se registró en selvas subperennifolias y sub-caducifolias durante ambas estaciones y con ambos cebos (carroña y excremento). Su abundancia en las trampas fue mayor en las selvas sub-perennifolias.

Distribución en México: Campeche, Chiapas, Chihuahua, Guerrero, Hidalgo, Jalisco, Estado de México, Michoacán, Morelos, Nayarit, Oaxaca, Puebla, San Luis Potosí, Sinaloa, Tamaulipas, Veracruz, Yucatán (Kohlmann 2003, Alvarado et al. 2018, SNIB-CONABIO 2016).

Distribución fuera de México: Costa Rica y Nicaragua (GBIF 2018).

Género Coprophanaeus Olsoufieff, 1924

Coprophanaeus (Coprophanaeus) corythus (Harold, 1863)

(Figura 40)

Sinonimias: Coprophanaeus telamon corythus (Harold, 1863) (recomb. por Arnaud 2002)

Coprophanaeus telamon nevinsoni Arnaud y Gámez, 2002. Nueva Sinonimia.

Coprophanaeus corythus (Harold). Nuevo Status. Edmonds y Zidek, 2010.
(Según Edmonds y Zidek 2010)

Observaciones: Esta especie fue capturada durante ambas estaciones, en selvas sun-perennifolias y subcaducifolias, utilizando trampas de caída con excremento o carroña como cebo. Aún así, su abundancia fue considerablemente mayor al cebar las trampas con carroña.

Distribución en México: Campeche, Chiapas, Hidalgo, Oaxaca, Puebla, Quintana Roo, Veracruz, Yucatán (Edmonds 2003, Edmonds y Zidek 2010, Alvarado et al. 2018)

Distribución fuera de México: Belice, Colombia, Costa Rica, Guatemala, Honduras, Nicaragua, Panamá, Venezuela (Cano 1998b, Edmonds y Zidek 2010).

Género Phanaeus MacLeay, 1819

Phanaeus (Notiophanaeus) endymion Harold, 1863 (Figura 41)

Sinonimias: Phanaeus (Notiophanaeus) endymion porioni Arnaud, 2001

Observaciones: Esta especie fue capturada principalmente durante la temporada de lluvias utilizando excremento y carroña como cebo, en selvas sub-caducifolias y sub-perennifolias. Durante la estación seca, se colectó un sólo individuo en una trampa cebada con carroña.

Distribución en México: Campeche, Chiapas, Michoacán, Quintana Roo, Tabasco, Veracruz, Yucatán (Alvarado et al. 2018, Arnaud 2002, Edmonds 2003).

Distribución fuera de México: Belice, El Salvador, Guatemala, Honduras, Estados Unidos (Arnaud 2002, Cano 1998b).

Phanaeus (Phanaeus) pilatei Harold, 1863 (Figura 42)

Sinonimias: Phanaeus (Phanaeus) wagneri pilatei Harold (Arnaud 2002)

Observaciones: $P$. pilatei fue colectada en selvas sub-perennifolias y sub-caducifolias, durante ambas estaciones, en trampas de caída cebadas con excremento o carroña. Aunque esta especie se distribuye ampliamente en Calakmul, fue capturada con mayor frecuencia en selvas sub-perennifolias durante la temporada de lluvias.

Distribución en México: Campeche, Chiapas, Quintana Roo, Yucatán (Alvarado et al. 2018, Morón et al. 1986, Edmonds 2003).

Distribución fuera de México: Guatemala (Cano 1998b).

Género Onthophagus Latreille, 1802

Onthophagus batesi Howden y Cartwright, 1963 (Figura 43)

Observaciones: $O$. batesi fue encontrado exclusivamente en selvas sub-perennifolias, durante ambas estaciones, al trabajar con trampas cebadas con excremento.

Distribución en México: Campeche, Chiapas, Colima, Guerrero, Hidalgo, Jalisco, Morelos, Oaxaca, Puebla, San Luis Potosí, Tabasco, Tamaulipas, Veracruz, Yucatán 
(Zunino 2003).

Distribución fuera de México: Antillas, Belice, Colombia, Costa Rica, El Salvador, Honduras, Nicaragua, Panamá, Estados Unidos (incluyendo Hawaii) (PulidoHerrera et al. 2009, GBIF 2018).

Onthophagus carpophilus Pereira y Halffter, 1961 (Figura 44)

Observaciones: Esta especie sólo fue registrada durante la temporada de lluvias, tanto en selvas sub-perennifolias como sub-caducifolias; en fruta fermentada, y en trampas cebadas con excremento o carroña.

Registros de campo: Los adultos de esta especie no sólo fueron colectados en trampas de caída, también se recolectó un individuo de una fruta fermentada en el suelo, una "bola de perro" Tabernaemontana alba (Apocynacea).

Distribución en México: Campeche, Chiapas, Jalisco, Oaxaca, Veracruz, Yucatán (Alvarado et al. 2018, Zunino 2003).

Distribución fuera de México: Belice (GBIF 2018).

\section{Onthophagus coscineus Bates, 1887}

(Figura 45)

Sinonimias: Onthophagus digitifer Boucomont, 1932

Observaciones: Esta especie sólo fue colectada durante la temporada de lluvias en trampas cebadas con excremento, tanto selvas sub-perennifolias como sub-caducifolias.

Distribución en México: Campeche, Chiapas (Navarrete y Halffter 2008).

Distribución fuera de México: Belice, Colombia, Costa Rica, Ecuador, Panamá, Perú (Latha et al. 2015, Pulido-Herrera et al. 2009).

\section{Onthophagus crinitus Harold, 1869 \\ (Figura 46)}

Observaciones: $O$. crinitus fue una de las especies numéricamente dominantes en este estudio.

Registros de campo: Los adultos no sólo se encontraron en trampas con cebo, también se colectaron varios individuos en excretas frescas de Mazama $s p$. (Artyodactila: Cervidae), en excremento de tapir Tapirus bairdii fresco, así como también al segundo día; En una excreta de carnívoro se encontró un escarabajo el primer día $\mathrm{y}$ otro el segundo.

Distribución en México: Campeche, Chiapas, Oaxaca, Tabasco, Veracruz (Zunino 2003).

Distribución fuera de México: Belice, Colombia, Costa Rica, El Salvador, Guatemala, Nicaragua, Panamá (Pulido-Herrera et al. 2009).

Onthophagus cyclographus Bates, 1887

(Figura 47)

Observaciones: $O$. cyclographus se colectó tanto en selvas sub-perennifolias como subcaducifolias, durante ambas estaciones, en trampas cebadas con excremento o carroña.
Distribución en México: Campeche, Chiapas, Quintana Roo, Yucatán (Alvarado et al. 2018, Navarrete y Halffter 2008, SNIB-CONABIO 2016).

Distribución fuera de México: Belice, Guatemala, Panamá (Cano 1998b, GBIF 2018).

Onthophagus landolti Harold, 1880

(Figura 48)

Observaciones: $O$. landolti sólo fue colectada en selvas sub-caducifolias, al trabajar con trampas de caída cebadas con excremento, tanto en la estación seca como en la lluviosa.

Distribución en México: Campeche, Chiapas, Hidalgo, Jalisco, Quintana Roo, Veracruz, Yucatán (Zunino 2003, SNIB-CONABIO 2016, GBIF 2018).

Distribución fuera de México: Belice, Colombia, Costa Rica, El Salvador, Estados Unidos, Guatemala, Nicaragua, Panamá, Venezuela (Pulido-Herrera et al. 2009).

Onthophagus longimanus Bates, 1887

(Figura 49)

Observaciones: $O$. longimanus fue capturado durante ambas estaciones, en trampas cebadas con excremento colocadas en selvas sub-perennifolias.

Distribución en México: Campeche, Chiapas, Veracruz, Yucatán (Alvarado et al. 2018, Zunino 2003).

Distribución fuera de México: Guatemala (Cano 1998b).

\section{Onthophagus maya Zunino, 1981}

(Figura 50)

Observaciones: Esta especie solo se registró durante la temporada de lluvias, en trampas con excremento como cebo, tanto en selvas sub.perennifolias como subcaducifolias.

Distribución en México: Campeche, Chiapas, Oaxaca, Quintana Roo, Veracruz (Zunino 2003).

Distribución fuera de México: Belice, Guatemala (Cano 1998b, Pulido-Herrera et al. 2009).

\section{Onthophagus rhinolophus Harold, 1869}

(Figura 51)

Observaciones: $O$ rhinolophus sólo se recolectó en selvas sub-perennifolias durante la temporada de lluvias (junio-julio), utilizando trampas cebadas con excremento.

Distribución en México: Campeche, Chiapas, Hidalgo, Oaxaca, Puebla, Tabasco, Veracruz (Zunino 2003, SNIBCONABIO 2016).

Distribución fuera de México: Guatemala, Panamá, Venezuela (Pulido-Herrera et al. 2009).

\section{Onthophagus yucatanus Delgado-Castillo, Peraza y Deloya, 2006 \\ (Figura 52)}

Observaciones: $O$. yucatanus se recolectó durante ambas estaciones, en selvas sub-perennifolias y sub- 
caducifolias usando trampas cebadas con excremento. Aún así, su frecuencia de captura fue considerablemente mayor durante la época de lluvias, en los meses de junio y julio.

Distribución en México: Campeche, Chiapas, Quintana Roo, Yucatán (Delgado-Castillo et al. 2006, SNIB-CONABIO 2016).

Distribución fuera de México: Belice, Guatemala (Latha et al. 2015, Pulido-Herrera et al. 2009).

\section{DISCUSIÓN \\ Los Scarabaeinae de Calakmul.}

Comparación con otras áreas de selva mesoamericana

En Calakmul los dos tipos de selva existente registraron en conjunto 47 especies de Scarabaeinae (49 si se cuentan Copris lugubris y Dichotomius maya colectados de excremento de vaca a orillas de la reserva, en acahual entre potreros y selva). Calakmul abarca selvas sub-perennifolias y selvas sub-caducifolias; se encontraron elementos representativos de ambos tipos de ecosistemas. La mayoría de los elementos coinciden con los que se encuentran en las selvas Lacandona y Maya, más algunos elementos adicionales de hábitats más secos característicos de la Península de Yucatán.

En el contexto de las selvas de Mesoamérica, se registró un total de 45 especies en El Petén (Guatemala) (Ponce 2004, Ponce-Santizo et al. 2006, Génier 2009, GonzálezAlvarado y Vaz-de-Mello 2014). En la depresión de la Selva Lacandona, en distintos tipos de selva siempre verde de la reserva de la biósfera de Montes Azules, se han llegado a colectar 48 especies (Navarrete y Halffter 2008, Barragán et al. 2011, Sánchez de Jesús et al. 2016, GonzálezAlvarado y Vaz-de-Mello 2014). En estos casos, no sólo se colocaron trampas en el bosque continuo dentro de las áreas protegidas, sino también en ambientes antropizados (i.e. guamiles o acahuales, potreros y fragmentos de bosque). En Palenque, en los remanentes de selva siempre verde de tamaño considerable que quedan, se han colectado 44 especies (Halffter et al. Datos no publicados). Por último, más al Norte del Istmo de Tehuantepec, en la región de Los Tuxtlas, se han registrado 48 especies (Estrada et al. 1993 y 1998, Favila y Díaz 1997, Morón y Blackaller 1997, Deloya y Morón 1998, Rivera-Cervantes y Halffter 1999, Génier 2009, Díaz et al. 2010, Barragán et al. 2011, Alvarado et al. 2014, González-Alvarado y Vaz-de-Mello 2014). A pesar de la perturbación que ha sufrido la región de Los Tuxtlas, incluye una fauna rica, sin duda asociada a las diferencias de nivel que se presentan en los tres volcanes de la región. Las capturas examinadas llegan hasta el nivel de los 1,400 m.s.n.m.

Fuera de México, en el límite Sur de la Zona de Transición Mexicana (ZTM), en selva siempre verde y vegetación modificada, se han registrado 50 especies (Escobar et al. 2008) en La Selva (Costa Rica), una estación biológica estrictamente protegida. Aunque antes de que se estableciera, el bosque primario fue muy perturbado y aún hoy no se recupera totalmente. Esto explica que el número de especies registrado no haya sido más alto, ya que en las selvas de Costa Rica se encuentran números superiores a los que se presentan en las selvas de México,

México forma parte de la Zona de Transición Mexicana, donde se solapan líneas de afinidad septentrional con líneas de afinidad neotropical. La historia biogeográfica de la Zona de Transición Mexicana es compleja y hoy se sabe que han existido por lo menos dos zonas subsecuentes con composición parcialmente distinta. El cambio entre ambas Zonas de Transición ocurrió aproximadamente en el Mioceno. Los paisajes de México tienen una participación equilibrada de linajes septentrionales y linajes Neotropicales, o bien dominio de alguno de estos linajes. El único paisaje donde solamente existen elementos de un origen es la parte superior de las cordilleras, a altitudes superiores a los 2,500 m.s.n.m. Allí solamente se encuentran linajes de Scarabaeinae de afinidad septentrional. En el interior de las selvas, los Scarabaeinae de origen neotropical de la Zona de Transición Mexicana corresponden al patrón de distribución Neotropical Típico. Los de origen septentrional, corresponden al patrón paleoamericano tropical.

Contra lo que podría pensarse, en los trópicos existe una fauna mixta, incluso una fauna mixta de origen muy antiguo. Indudablemente, son más numerosos y más variados los elementos de afinidad neotropical, pero existen por lo menos dos géneros de origen septentrional con numerosas especies (Copris y Onthophagus), especialmente el segundo género. Un tercer género, Sisyphus está representado por una sola especie en los paisajes tropicales y otra fuera de ellos.

Se supone que la penetración de elementos de origen neotropical en la Zona de Transición Mexicana es tan antigua como la de elementos septentrionales, muy posiblemente anterior al Mioceno. Si hay marcada preponderancia de linajes Neotropicales se debe a razones ecológicas: hasta el Mioceno la Zona de Transición es de clima tropical, lo que favorecía la entrada de elementos del norte de Sudamérica que estaban adaptados a un clima tropical.

La penetración de linajes de origen neotropical en la Zona de Transición ha sido más accidentada que la de linajes septentrionales. La expansión de linajes de Sudamericanos hacia Centroamérica y en general hacia la ZTM ocurrió en dos tiempos, separados por un intermedio, durante el cual sólo pasaron los saltadores de islas (Simpson 1953). Hasta la reconformación del puente de Panamá, la migración de elementos Neotropicales fue altamente aleatoria. Esta comunicación se restablece hace 15-13 millones de años. Una vez restablecida, se inicia el gran intercambio de las Américas, que para los insectos es dominante de Sudamérica hacia Norteamérica, aunque también se presentan movimientos en sentido contrario. Los elementos neotropicales de penetración más reciente son todos exclusivos del bosque tropical, muchas veces asociados a los monos y su excremento.

En el Cenozoico, las selvas tropicales húmedas del norte y noreste de la región Neotropical fueron importantes centros de diversificación de linajes de Scarabaeinae 
característicos de las selvas siempre verdes actuales. Tanto para algunos linajes procedentes de áreas septentrionales, como sobre todo para linajes de origen y afinidad neotropical. Lo anterior hace contraste con otra fauna neotropical que evoluciona en el Sur/Sureste de Sudamérica, área de los abundantes ichnofósiles de Argentina (bolas-nido de Scarabaeinae: Coprinisphaera) del Cenozoico inferior. En lo que respecta a las selvas tropicales de la ZTM el aporte de Scarabaeinae llega muy posiblemente entre OligocenoMioceno (Morrone 2006 y 2015).

Existe un gran cuerpo de literatura que sugiere que los Scarabaeinae son particularmente vulnerables a la deforestación y a la fragmentación del bosque con pérdida abrupta de una parte de las especies al quitarse los árboles e incrementar la insolación (Las citas se inician con: Halffter et al. 1992, Nichols et al. 2007). Estos fenómenos se pueden asociar con la historia evolutiva de la subfamilia, historia que ha transcurrido en el interior de las selvas tropicales desde el principio del Cenozoico. Junto con la fauna de Scarabaeinae de las selvas tropicales húmedas, existe otra fauna de lugares más abiertos, que por lo general pertenece a los mismos géneros, pero a linajes totalmente distintos.

Como se ha indicado, la comunicación entre las tierras del Viejo Mundo y Norte América, y a su vez la Zona de Transición, no fue igualmente difícil a la conexión entre la Zona de Transición y Sudamérica. Beringia y el puente del Atlántico Norte conectan Norteamérica con Eurasia. A su vez, el actual México es una península de Norteamérica. Esta península ha tenido un contacto con Centro y Sudamérica mucho más accidentado, que se interrumpe por buena parte del Cenozoico. Cuando se vuelve a restablecer el contacto la migración de elementos Neotropicales es masiva.

Los Scarabaeinae de las selvas tropicales de la Zona de Transición están adaptados a múltiples recursos; frutos en descomposición, casos de necrofagia o el consumo de elementos muy especializados como diplópodos. Estos casos de divergencia de la coprofagia se presentan con mayor frecuencia aquí que en cualquier otra parte del mundo. Se puede asociar este fenómeno, esta riqueza de adaptaciones fuera del patrón predominante, a la supervivencia de esta fauna y su adaptación a nuevas condiciones en el período del Plioceno-Pleistoceno; período durante el cual desaparece gran parte de la megafauna de mamíferos de la Zona de Transición. Continuando la idea de una adaptación de los elementos de selva a cambios en la misma como un fenómeno muy antiguo, se puede esperar una alta tasa de extinción de Scarabaeinae al modificarse la selva.

Los patrones de diversidad encontrados revelaron heterogeneidad espacial y temporal en la distribución de las especies y de los individuos de la subfamilia Scarabaeinae en Calakmul; un bosque tropical continuo sin alteraciones antrópicas recientes. En el estudio de paisajes para uso humano, el fragmento o área remanente más extensa y mejor conservada (sin alteraciones humanas aparentes o recientes) se toma como línea de base para evaluar la magnitud del impacto antrópico sobre la biodiversidad. Los resultados de este trabajo advierten sobre la variación natural sustancial que existe dentro de los bosques preservados y que no siempre se tiene en cuenta.

Hasta la fecha, este ha sido el único estudio sobre escarabajos del estiércol de la subfamilia Scarabaeinae en la RBC y ha generado información de referencia sobre las especies que allí se encuentran. La información obtenida es fundamental para monitorear la biodiversidad y evaluar la integridad ecológica de los ecosistemas. Más aún si consideramos que la recopilación de datos puede ser un elemento crítico en el desarrollo de planes para la conservación de la biodiversidad. Futuras estrategias de manejo para la conservación e investigaciones pueden disponer de los resultados de este trabajo.

\section{AGRADECIMIENTOS}

Victoria Capello agradece a Mario Zunino y a Leonardo Delgado su disposición para revisar parte del material colectado y su asistencia en la identificación. A Augusto Mandujano su asesoramiento durante la edición de las fotografías. A Enio Cano la versión impresa de su tesis. A Albert Chand-Zul y a Sara Oliveros por abrirme su casa. A Fernando Gervasio y a Mauro Barrientos, su participación en campo. A Diego por su invaluable colaboración en el estudio de la vegetación y a toda la familia Meneses por recibirme en Dos Lagunas Sur. A Fernando Escobar-Hernández por su apoyo durante el trabajo de campo, con la identificación del material y las fotografías con el microscopio. A Alfonso Aceves por las fotografías. Reconocemos especialmente a las instituciones que de una forma u otra apoyaron el desarrollo de este trabajo. En particular al Consejo Nacional de Ciencia y Técnica (CONACYT) que otorgó una beca a Victoria Capello para realizar sus estudios de posgrado entre 2013- 2015. Agradezco a The Rufford Foundation por el financiamiento otorgado (Rufford Small Grants ref: 15762-1). A IDEA WILD por el equipamiento concedido. A la Comisión Nacional de Áreas Protegidas (CONANP), Dirección de la Reserva de la Biosfera de Calakmul, el apoyo logístico durante la etapa de campo. Al Consejo Regional Indígena y Popular de Xpujil S.C. (CRIPX) y a COMBIOSERVE por su apoyo desde Xpujil. Finalmente, agradecemos a los ejidos Arroyo Negro, Conhuás y Dos Lagunas Sur; así como a la CONANP y a la Secretaría de Medio Ambiente y Recursos Naturales (SEMARNAT), por los permisos otorgados para la realización del trabajo. Agradecemos al Dr. Jorge Llorente Bousquets por sus contribuciones a la entomología.

\section{LITERATURA CITADA}

Alvarado, F., F., Escobar, and J. Montero-Muñoz. 2014. Diversity and biogeographical makeup of the dung beetle communities inhabiting two mountains in the Mexican Transition Zone. Organisms Diversity and Evolution 14(1): 105-114.

Alvarado, F., F., Escobar, D. R., Williams, V., ArroyoRodríguez, and F. Escobar-Hernández. 2018. The role 
of livestock intensification and landscape structure in maintaining tropical biodiversity. Journal of Applied Ecology 55(1): 185-194.

Andresen, E., and S. G. Laurance. 2007. Possible indirect effects of mammal hunting on dung beetle assemblages in Panama. Biotropica 39(1): 141-146.

Arnaud, P. 2002. Phanaeini: Dendropaemon, Tetramereia, Homalotarsus, Megatharsis, Diabroctis, Coprophanaeus, Oxysternon, Phanaeus, Sulcophanaeus. Hillside books, Canterbury.

Barragán, F., C. E., Moreno, F., Escobar, G., Halffter, and D. Navarrete. 2011. Negative impacts of human land use on dung beetle functional diversity. PloS one 6(3) e17976. https://doi.org/10.1371/journal.pone.0017976

Cambefort, Y., and I. Hanski. 1991. Dung beetle ecology. Princeton University Press, Princeton.

Cano, E. B. 1998a. Deltochilum valgum acropyge Bates (Coleoptera: Scarabaeidae: Scarabaeinae): habits and distribution. The Coleopterists' Bulletin 52(2): 174-178.

Cano, E. B. 1998b. Escarabajos copro-necrófagos (Coleoptera: Scarabaeidae: Scarabaeinae) de la Reserva de la Biósfera Maya, Petén, Guatemala: taxonomía, diversidad, asociación de hábitat y su uso en programas de monitoreo - Tesis de Maestría, Facultad de Ciencias y Humanidades, Universidad del Valle de Guatemala, Guatemala.

Carabias, J., E., Provencio, J., De La Maza, y J. B. Rodríguez. 2000. Programa de manejo reserva de la Biosfera de Calakmul. Instituto Nacional de Ecología, México DF, México.

Comisión Nacional de Áreas Naturales Protegidas (CONANP). 2001. Programa de Trabajo 2001-2006. México, D.F. 64 pp.

SNIB-CONABIO (Sistema Nacional de Información sobre Biodiversidad Y Comisión Nacional para el Conocimiento y Uso de la Biodiversidad). 2016. Base de Datos del SNIB-CONABIO 2016. México, Ciudad de México.

Culot, L., E., Bovy, F. Z., Vaz-de-Mello, R., Guevara, and M. Galetti. 2013. Selective defaunation affects dung beetle communities in continuous Atlantic rainforest. Biological Conservation 163:79-89.

Cupello, M. 2018. On the types species of the New World dung beetle Género Canthidium Erichson, 1847 (Coleoptera: Scarabaeidae: Scarabaeinae), with an annotated checklist of species. Zootaxa 4388(4): 451486.

Delgado, L., y B. Kohlmann. 2007. Revisión de las especies del género Uroxys Westwood de México y Guatemala (Coleoptera: Scarabaeidae: Scarabaeinae). Folia Entomológica Mexicana 46(1): 1-36.

Delgado, L., L. N., Peraza, and C. DeLoya. 2006. Onthophagus yucatanus, a new species of the clypeatus group from Mexico and Guatemala (Coleoptera: Scarabaeidae). Florida Entomologist 89(1): 6-9.
Deloya, C., y M. A. Morón. 1998. Nuevas especies de Phyllophaga Harris (Coleoptera: Melolonthidae) de Morelos, Puebla y Chiapas, México. Folia Entomológica Mexicana 104(1): 109-119.

Deloya, C., and L. N. Peraza-Flores. 2005. Pedaridium maya (Coleoptera: Scarabaeidae): first record in Yucatán, Mexico. Florida entomologist 88(3): 341.

Díaz, A., E., Galante, and M. E. Favila. 2010. The effect of the landscape matrix on the distribution of dung and carrion beetles in a fragmented tropical rain forest. Journal of Insect Science 10(1): 81-97.

Díaz-Gallegos, J. R., J. F., Mas, y A. V. Montes. 2008. Monitoreo de los patrones de deforestación en el Corredor Biológico Mesoamericano, México. Interciencia 33(12): 882-890.

Edmonds, W. D. 2003. Tribu Phanaeini. En: Atlas de los escarabajos de México. Coleoptera: Lamellicornia Vol. II Familias Scarabaeidae, Trogidae, Passalidae y Lucanidae. Ed. Morón, M. A. Argania, Barcelona. Pp 58-65.

Edmonds, W. D., and J. Zídek. 2010. A taxonomic review of the neotropical Género Coprophanaeus Olsoufieff, 1924 (Coleoptera: Scarabaeidae, Scarabaeinae) Insecta Mundi 129: 1-111.

Escobar, F., G. Halffter, Á. Solís, V. Halffter, and D. Navarrete. 2008. Temporal shifts in dung beetle community structure within a protected area of tropical wet forest: a 35-year study and its implications for longterm conservation. Journal of Applied Ecology 45(6): 1584-1592.

Estrada, A., G., Halffter, R., Coates-Estrada, and D. A. Meritt. 1993. Dung beetles attracted to mammalian herbivore (Alouatta palliata) and omnivore (Nasua narica) dung in the tropical rain forest of Los Tuxtlas, Mexico. Journal of Tropical ecology 9(1): 45-54.

Estrada, A., R., Coates-Estrada, A. A., Dadda, and P. Cammarano. 1998. Dung and carrion beetles in tropical rain forest fragments and agricultural habitats at Los Tuxtlas, Mexico. Journal of Tropical Ecology 14(5): 577-593.

Favila, M. E., y A. Díaz. 1997. Escarabajos coprófagos $y$ necrófagos. Historia Natural de Los Tuxtlas. Universidad Nacional Autónoma de México, México DF, México, pp. 383-384.

Feer, F., and O. Boissier. 2015. Variations in dung beetle assemblages across a gradient of hunting in a tropical forest. Ecological Indicators 57: 164-170.

García Gil, G., J. L., Palacio Prieto, y M. A. Ortiz Pérez. 2002. Reconocimiento geomorfológico e hidrográfico de la Reserva de la Biósfera Calakmul, México. Investigaciones geográficas 48: 7-23.

GBIF - The Catalogue of Life Partnership 2018. Catalogue of Life. Checklist dataset https://doi.org/10.15468/ rffz4x accessed via GBIF.org on 2018-05-31.

Génier, F. 2009. Le genre Eurysternus Dalman, 1824 (Scarabaeidae: Scarabaeinae: Oniticellini), revision 
taxonomique et clés de determination illustrées. Series Faunística No 85. Pensoft ed. Sofia, Bulgaria.

Génier, F. 2012. A new species and notes on the subgénero Deltochilum (Deltochilum) Eschscholtz, 1822 (Coleoptera: Scarabaeidae: Scarabaeinae: Deltochilini). Zootaxa 3357(1): 25-36.

González-Alvarado, A., and F. Z. Vaz-de-Mello. 2014. Taxonomic review of the subgenus Hybomidium Shipp 1897 (Coleoptera: Scarabaeidae: Scarabaeinae: Deltochilum). Annales de la Société Entomologique de France (Nouvelle Série) 50(3-4): 431-476.

Halffter, G. 1961. Monografía de las especies norteamericanas del género Canthon Hoffsg. (Coleoptera, Scarabaeidae). Ciencia (México) 20(912): $225-320$.

Halffter, G. 1998. A strategy for measuring landscape biodiversity. Biology International 36: 3-17.

Halffter, G. 2003. Tribu Scarabaeini. En: Atlas de los escarabajos de México. Coleoptera: Lamellicornia Vol. II Familias Scarabaeidae, Trogidae, Passalidae y Lucanidae. Ed. Morón, M. A. Argania, Barcelona. Pp 21-43.

Halffter, G., and M. E. Favila. 1993. The Scarabaeinae (Insecta: Coleoptera) an animal group for analyzing, inventorying and monitoring biodiversity in tropical rainforest and modified landscapes. Biology International 27:15-21.

Halffter, G., M. E., Favila, and V. Halffter. 1992. A comparative study of the structure of the scarab guild in Mexican tropical rain forests and derived ecosystems. Folia Entomológica Mexicana 84: 131-156.

Halffter, G., and E. G. Matthews. 1966. The natural history of dung beetles of the subfamily Scarabaeinae (Coleoptera, Scarabaeidae). Folia Entomológica Mexicana 12-14: 1-312.

Halffter, G., y M. Rös. 2013. A strategy for measuring biodiversity. Acta Zoológica Mexicana (nueva serie) 29(2): 400-411.

Herrera, E. R. T., K., Vulinec, C., Knogge, and E. W. Heymann. 2002. Sit and wait at the source of dung-an unusual strategy of dung beetles. Ecotropica 8(1):8788.

Howden, H. F. 1965. A second New World species of Sisyphus Latreille (Coleoptera: Scarabaeidae). The Canadian Entomologist 97(8): 842-844.

Instituto Nacional de Ecología. 1999. Programa de Manejo de la Reserva de la Biosfera Calakmul, México. 272 pp

Instituto Nacional de Estadística y Geografía (INEGI). 2000. Conjunto de datos vectorial edafológico en escala: 1:250000 Serie I continuo nacional. Instituto Nacional de Estadística y Geografía, México.

Jacobs, J., I., Nole, S., Palminteri, and B. Ratcliffe. 2008. First come, first serve:" sit and wait" behavior in dung beetles at the source of primate dung. Neotropical Entomology 37(6): 641-645.
Kohlmann, B. 2003. Tribu Coprini. En: Atlas de los escarabajos de México. Coleoptera: Lamellicornia Vol. II Familias Scarabaeidae, Trogidae, Passalidae y Lucanidae. Ed. Morón, M. A. Argania, Barcelona. Pp 45-58.

Kohlmann, B., y A. Solís. 2006. El género Canthidium (Coleoptera: Scarabaeidae) en Norteamérica. Giornale Italiano di Entomologia 53(11): 235-295.

Kohlmann, B., and F. Z. Vaz-de-Mello. 2018. A new key for the species of Ateuchus Weber (Coleoptera: Scarabaeidae: Scarabaeinae) occurring in Mexico, with a description of the first North American inquiline species from a rodent burrow (Rodentia: Geomydae) and new distribution records. Revista Brasileira de Entomologia 62(2): 131-134.

Larsen, T. H., and A. Forsyth. 2005. Trap Spacing and Transect Design for Dung Beetle Biodiversity Studies. Biotropica 37(2): 322-325.

Larsen, T. H., A., Lopera, and A. Forsyth. 2006. Extreme trophic and habitat specialization by Peruvian dung beetles (Coleoptera: Scarabaeidae: Scarabaeinae). The Coleopterists Bulletin 60(4): 315-324.

Latha, T., P. Y., Huang, G. A., Perez, and I. O. Paquiul. 2016. Dung beetle assemblage in a protected area of Belice: A study on the consequence of forest fragmentation and isolation. Journal of Entomology and Zoology Studies 4(1): 457-463.

Martínez, E., y C. Galindo-Leal. 2002. La vegetación de Calakmul, Campeche, México: clasificación, descripción y distribución. Boletín de la Sociedad Botánica de México (71): 7-32.

Morón, M.A. 2003. Subtribu Sisyphina. En: Atlas de los escarabajos de México. Coleoptera: Lamellicornia Vol. II Familias Scarabaeidae, Trogidae, Passalidae y Lucanidae. Ed. Morón, M. A. Argania, Barcelona. Pp 43-44.

Morón, M.A. 2003. Tribu Eurysternini. En: Atlas de los escarabajos de México. Coleoptera: Lamellicornia Vol. II Familias Scarabaeidae, Trogidae, Passalidae y Lucanidae. Ed. Morón, M. A. Argania, Barcelona. Pp 44-45.

Morón, M. A., y R. A. Terrón. 1984. Distribución altitudinal y estacional de los insectos necrófilos en la Sierra Norte de Hidalgo, México. Acta Zoológica Mexicana (3): 1-47

Morón, M. A., J. F. Camal, y O. Canul. 1986. Análisis de la entomofauna necrófila del área Norte de la Reserva de la Biosfera" Sian Ka'an," Quintana Roo, México. Folia Entomológica Mexicana 69: 83-98.

Morón, M. A., y J. Blackaller. 1997. Melolonthidae y Scarabaeidae [pp. 227-243]. Historia Natural de Los Tuxtlas. E. González Soriano, R. Dirzo, and RC Vogt (eds.). Universidad Nacional Autónoma de México, Ciudad de México, México.

Morrone, J. J. 2006. Biogeographic areas and transition zones of Latin America and the Caribbean islands based on panbiogeographic and cladistic analyses of the 
entomofauna. Annual Review of Entomology 51: 467494.

Morrone, J. J. 2015. Biogeographical regionalisation of the Andean region. Zootaxa 3936(2): 207-236.

Navarrete, D., and G. Halffter. 2008. Dung beetle (Coleoptera: Scarabaeidae: Scarabaeinae) diversity in continuous forest, forest fragments and cattle pastures in a landscape of Chiapas, Mexico: the effects of anthropogenic changes. Biodiversity and Conservation 17(12): 2869-2898.

Nichols, E. S., and T. A. Gardner. 2011. Dung beetles as a candidate study taxon in applied biodiversity conservation research. Ecology and evolution of dung beetles. John Wiley \& Sons, Hoboken. 267-291.

Nichols, E., T. A., Gardner, C. A., Peres, S., Spector, and The Scarabaeinae Research Network. 2009. Codeclining mammals and dung beetles: an impending ecological cascade. Oikos 118(4): 481-487.

Nichols, E., T., Larsen, S., Spector, A. L., Davis, F., Escobar, M., Favila, K., Vulinec, and The Scarabaeinae Research Network. 2007. Global dung beetle response to tropical forest modification and fragmentation: a quantitative literature review and meta-analysis. Biological Conservation 137(1): 1-19.

Nichols, E., S., Spector, J., Louzada, T., Larsen, S., Amezquita, M. E., Favila, and The Scarabaeinae Research Network. 2008. Ecological functions and ecosystem services provided by Scarabaeinae dung beetles. Biological conservation 141(6): 1461-1474.

Padilla-Gil, D. N., and G. Halffter. 2007. Biogeography of the areas and Canthonini (Coleoptera: Scarabaeidae) of dry tropical forest in Mesoamerica and Colombia. Acta zoológica mexicana 23(1): 73-108.

Pereira, P. F. S., M. A., Vulcano, y A. Martinez. 1960. O genero Bdelyrus Harold, 1869. Actas Trab. del Primer Congr. Sudamericano Zool., Vol. 3, pp. 155-164. La Plata.

Ponce, G. 2004. Dispersión de semillas por mono araña (Ateles geoffroyi), saraguate negro (Alouatta pigra) $y$ escarabajos coprófagos en el Parque Nacional Tikal, Guatemala. Tesis, Departamento de Biología, Universidad del Valle de Guatemala. Ciudad de Guatemala, Guatemala.

Ponce-Santizo, G., E., Andresen, E., Cano, y A. D. Cuarón. 2006. Dispersión Primaria de Semillas por Primates y Dispersión Secundaria por Escarabajos Coprófagos en

Recibido: 7 de junio 2019

Aceptado: 1 de julio 2019
Tikal, Guatemala 1. Biotropica: The Journal of Biology and Conservation 38(3): 390-397.

Pulido-Herrera, L. A., M. Zunino, y A. Melic. 2007. Catálogo preliminar de los Onthophagini de América (Coleoptera: Scarabaeinae). Escarabajos, diversidad y conservación biológica. Ensayos en homenaje a Gonzalo Halffter. m3m - Monografía Tercer Milenio 7:93-129.

Rivera-Cervantes, L. E., y G. Halffter. 1999. Monografía de las especies mexicanas de Canthon del subgénero Glaphyrocanthon (Coleoptera: Scarabaeidae; Scarabaeinae). Acta Zoológica Mexicana (nueva serie) 77: 23-150.

Sánchez-de-Jesús, H. A., V., Arroyo-Rodríguez, E., Andresen, and F. Escobar. 2016. Forest loss and matrix composition are the major drivers shaping dung beetle assemblages in a fragmented rainforest. Landscape ecology 31(4): 843-854.

Silva, F. A., J., Louzada, and F. Vaz-De-Mello. 2015. A revision of the Deltochilum subgenus Aganhyboma Kolbe, 1893 (Coleoptera: Scarabaeidae: Scarabaeinae). Zootaxa 3925(4): 451-504.

Simpson, G. G. 1953. The major features of evolution. Columbia Univ. Press, New York, 434 pp.

Solís, A., y B. Kohlmann. 2004. El género Canthidium (Coleoptera: Scarabaeidae) en Costa Rica. Giornale Italiano di Entomologia 11(52): 1-73.

Solís, A., and B. Kohlmann. 2012. Checklist and distribution atlas of the Scarabaeinae (Coleoptera: Scarabaeidae) of Costa Rica. Zootaxa 3482(1): 1-32.

Spector, S. 2006. Scarabaeinae dung beetles (Coleoptera: Scarabaeidae: Scarabaeinae): an invertebrate focal taxon for biodiversity research and conservation. The Coleopterists Bulletin 60(mo5): 71-83.

Tun-Dzul, F. J., H., Vester, R., Durán García, y B. Schmook. 2008. Estructura arbórea y variabilidad temporal del NDVI en los" bajos inundables" de la Península de Yucatán, México. Polibotánica 25: 69-90.

Vaz-De-Mello, F. Z., G., Halffter, and V. Halffter. 2004. A new species of Pedaridium Harold from Mexico and Guatemala (Coleoptera: Scarabaeidae: Scarabaeinae: Coprini: Ateuchina). The Coleopterists Bulletin 58(2): 247-252.

Vaz-De-Mello, F. Z. 2008. Synopsis of the new subtribe Scatimina (Coleoptera: Scarabaeidae: Scarabaeinae: Ateuchini), with descriptions of twelve new genera and review of Génieridium, new genus. Zootaxa 1955: 1-75.

Vulinec, K., D. J., Mellow, and C. R. V. da Fonseca. 2007. Arboreal foraging height in a common neotropical dung beetle, Canthon subhyalinus Harold (Coleoptera: Scarabaeidae). The Coleopterists Bulletin 61(1): 75-81.

Zunino, M. 2003. Tribu Onthophagini. En: Atlas de los escarabajos de México. Coleoptera: Lamellicornia Vol. II Familias Scarabaeidae, Trogidae, Passalidae y Lucanidae. Ed. Morón, M. A. Argania, Barcelona. Pp 66-74. 

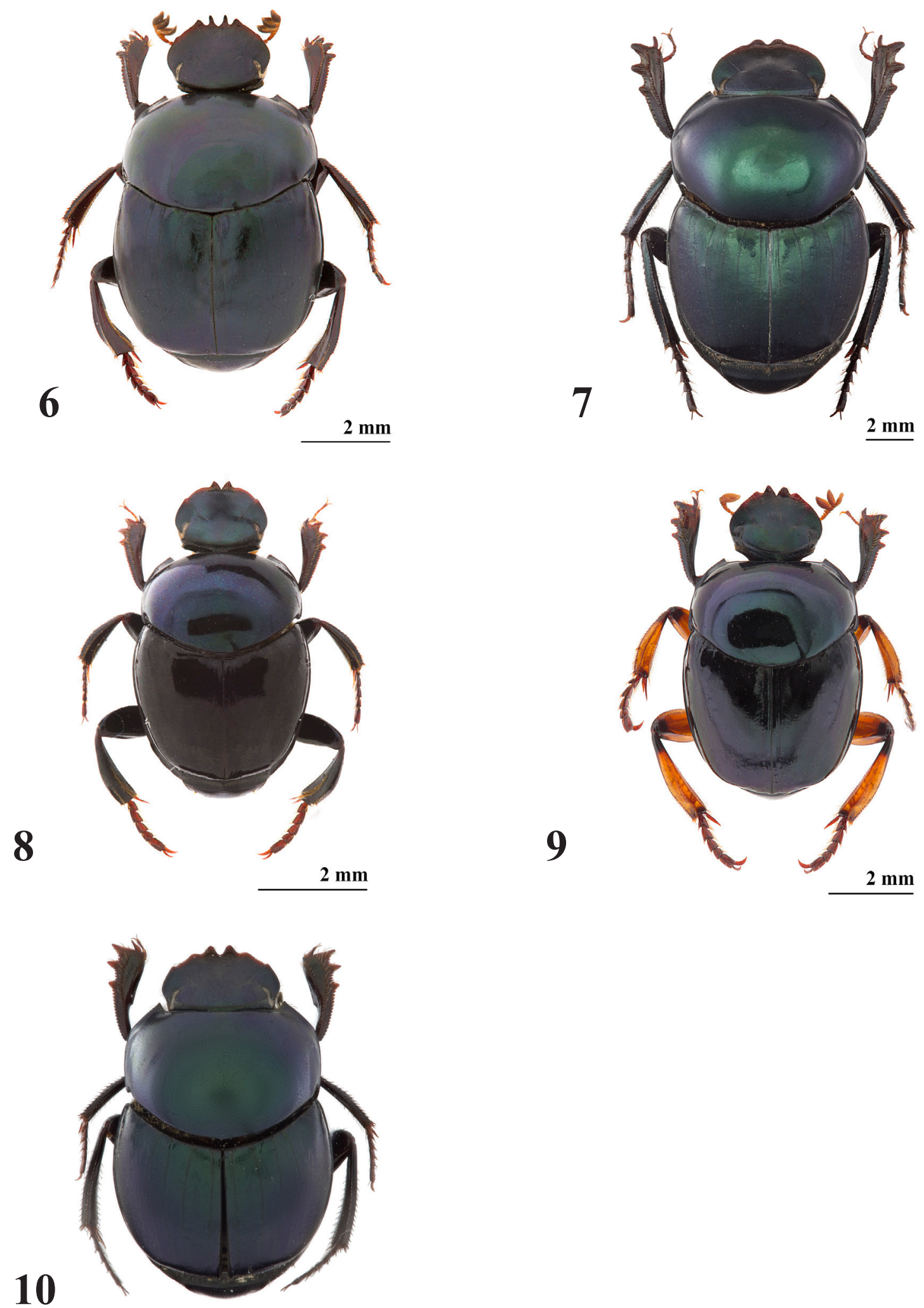

$2 \mathrm{~mm}$

Figuras 6-10. 6. Canthon (Canthon) cyanellus, 7. C. (C.) indigaceus chiapas, 8. C. (Glaphyrocanthon) euryscelis, 9. C. (Gl.) femoralis, 10. C. (Gl.) leechi. 

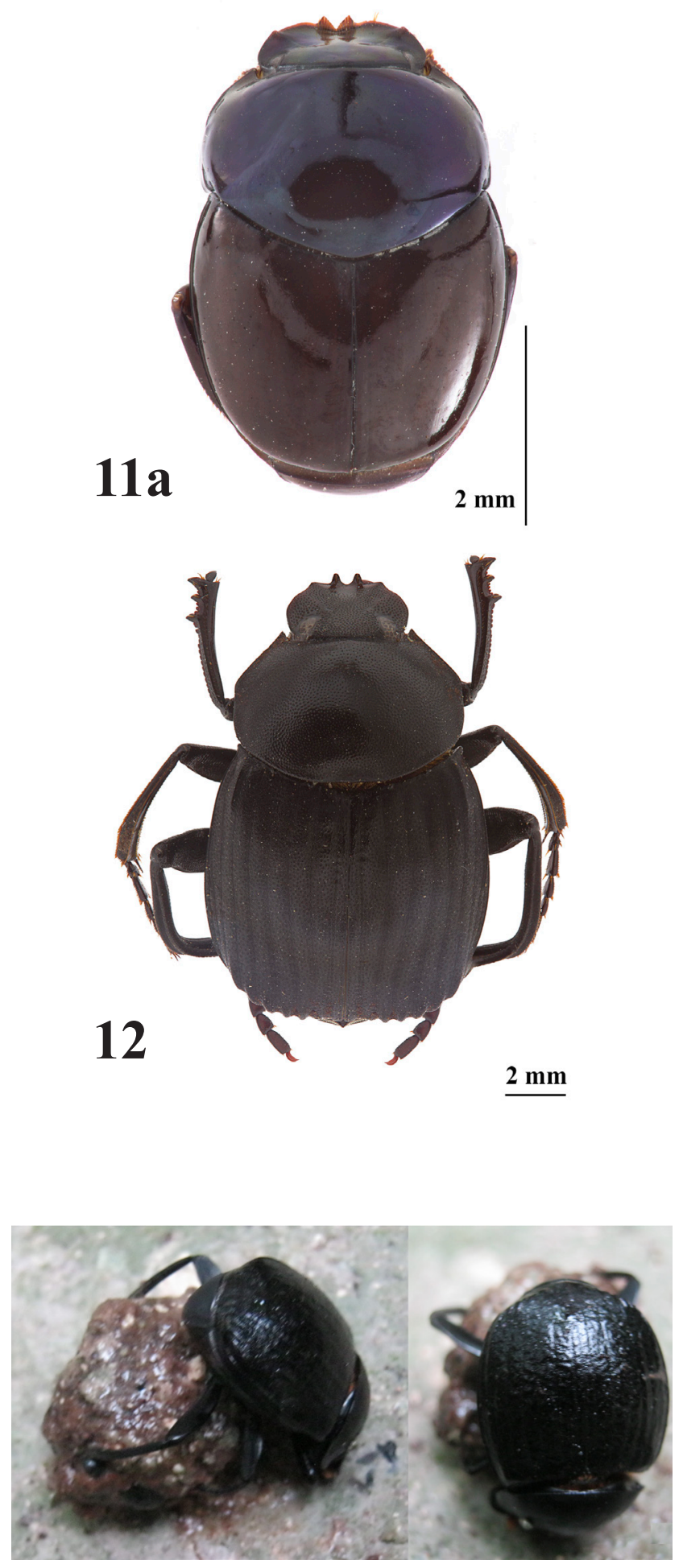

$13 b$

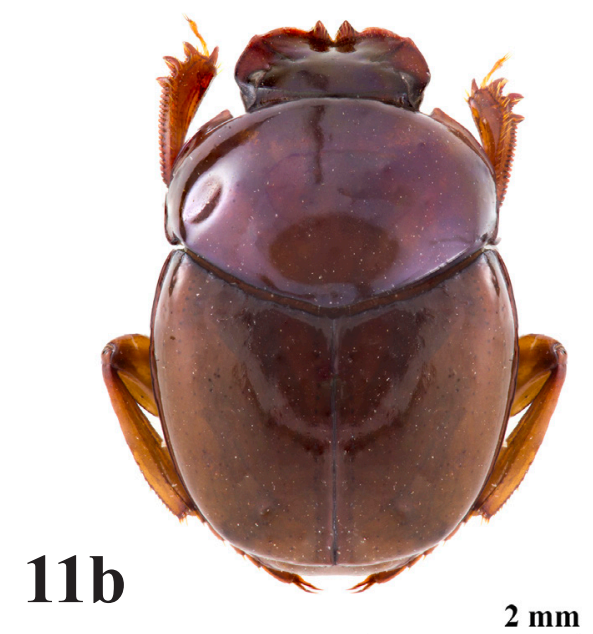

$13 \mathbf{a}$
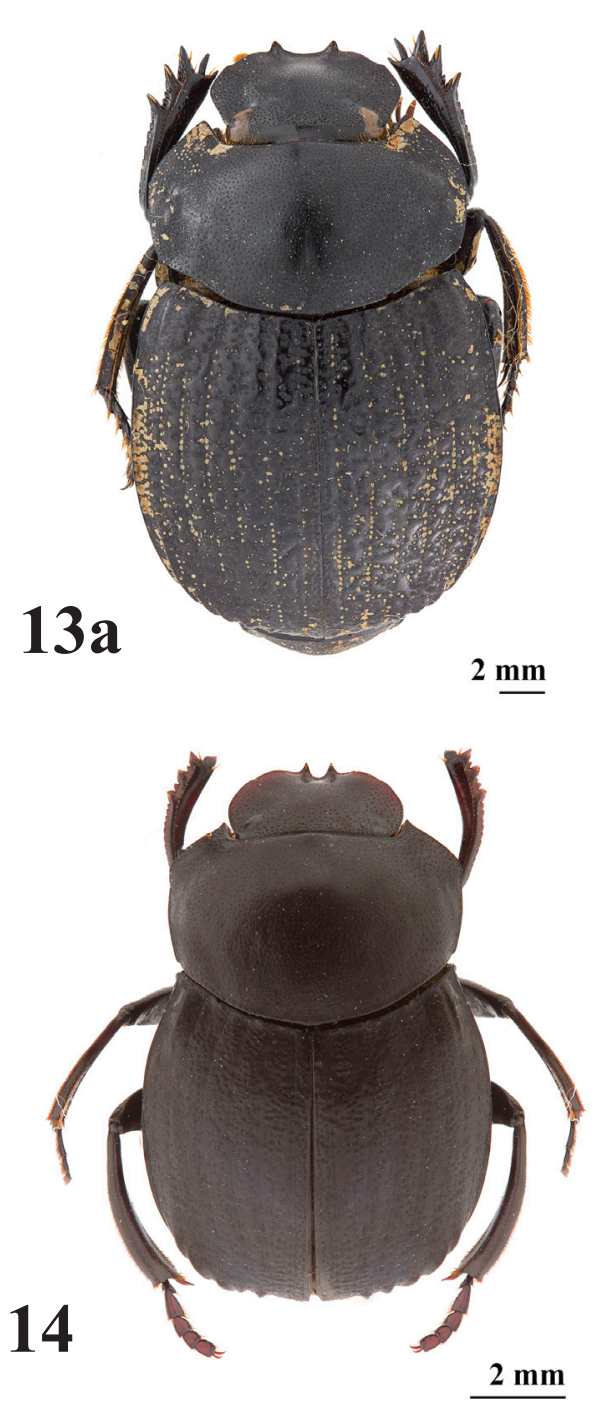

Figuras 11-14. 11. a y b $C$. (Gl.) subhyalinus; ilustrando la variación en la coloración de los élitros que se encuentra en Calakmul. 12. Deltochilum (Aganhyboma) acropyge, 13a y b. D. (Deltochilum) scabriusculum scabriusculum, $13 \mathbf{b}$. Deltochilum scabriusculum rodando una bola de carne de cascabel (Crotalus sp.). 14. D. (Deltohyboma) pseudoparile, 

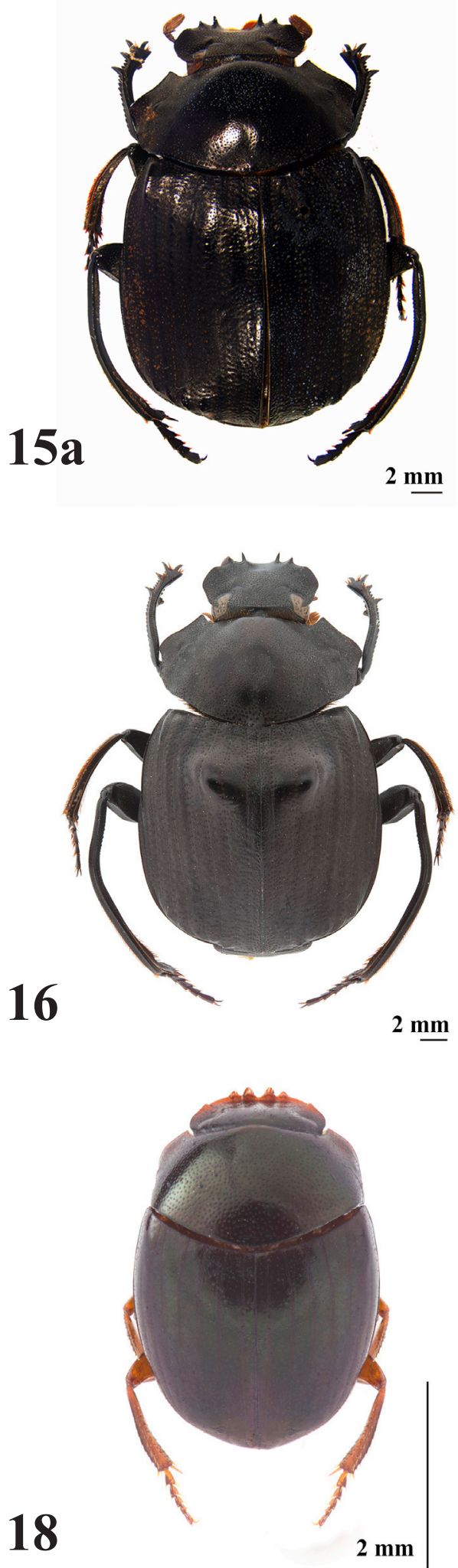
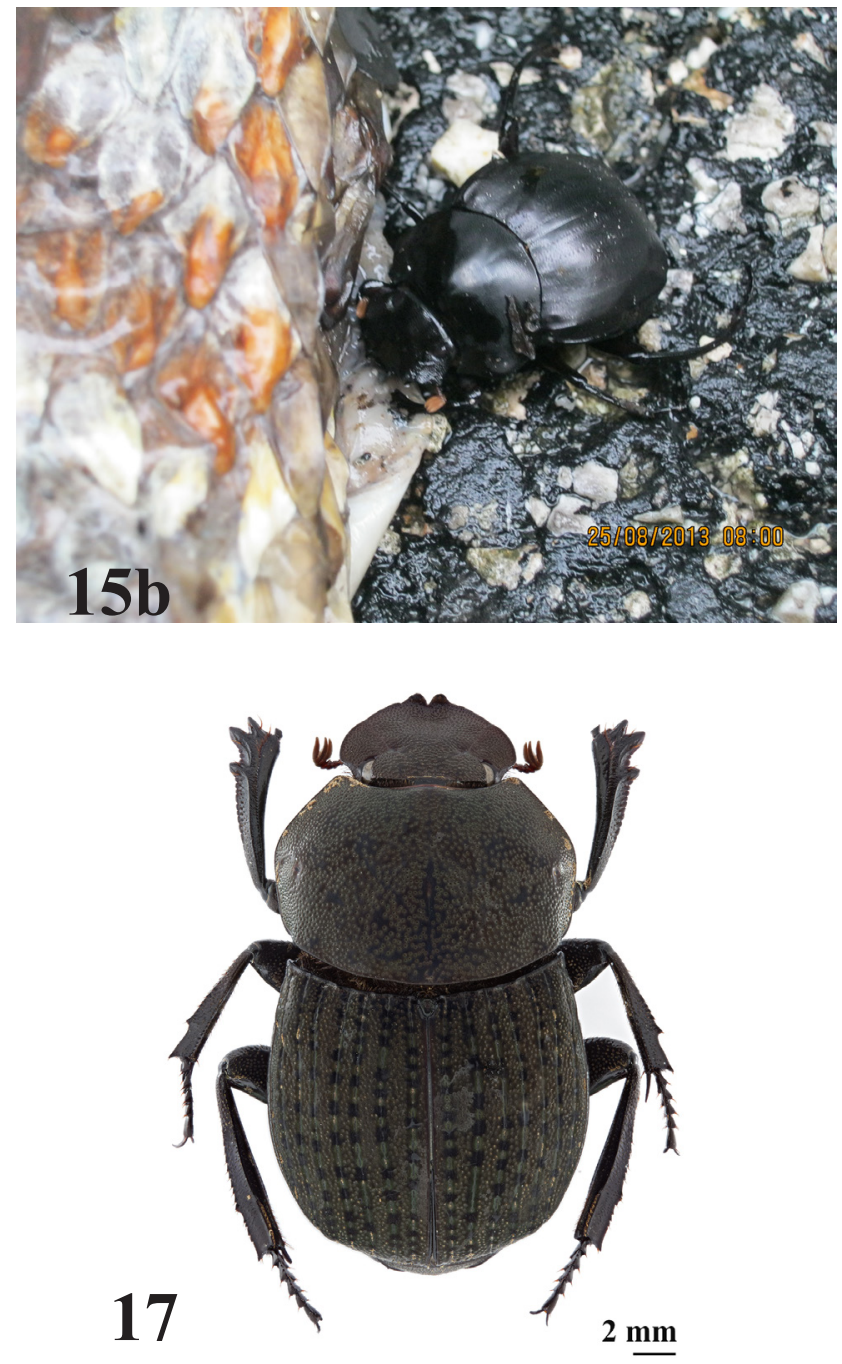

Figuras 15a-18. 15a. D. (Hybomidium) lobipes, 15b. Deltochilum lobipes cortando carne del cadáver de una cascabel (Crotalus sp.). 16. D. (H.) carrilloi, 17. Megathoposoma candezei, 18. Pseudocanthon perplexus. 

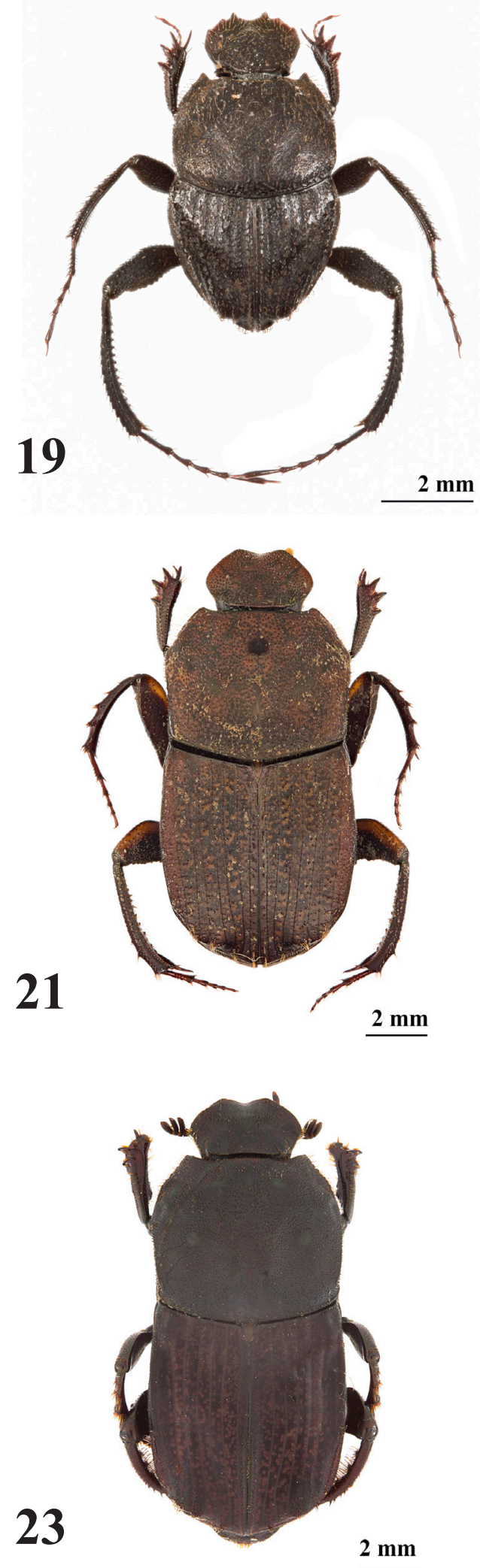
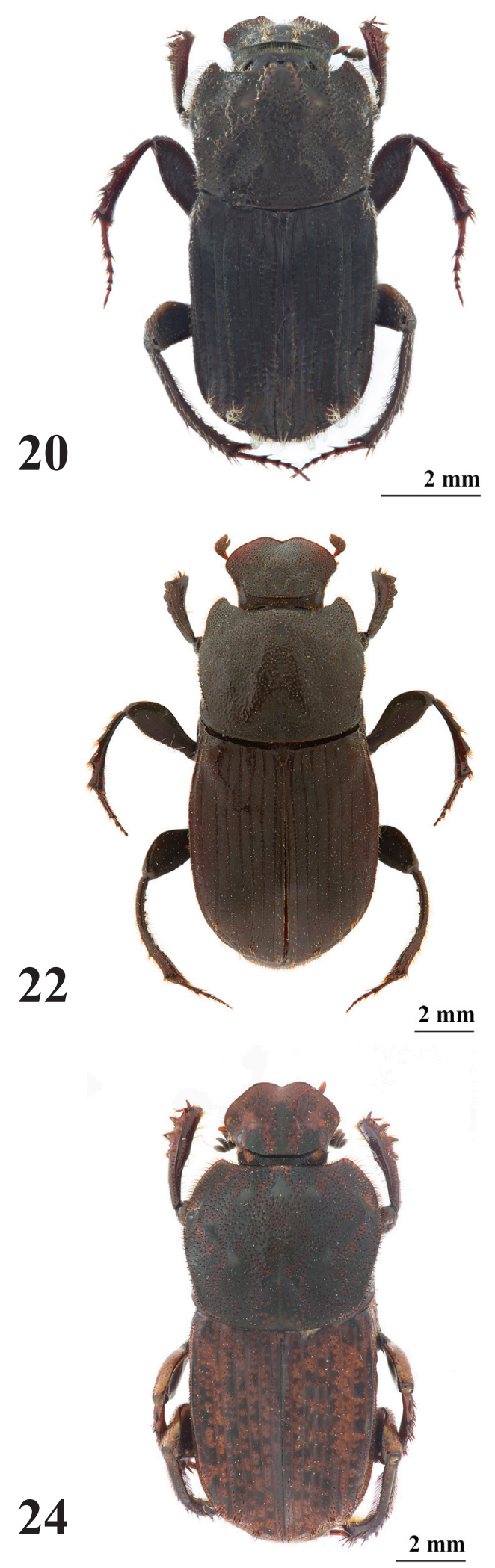

Figuras 19-24. 19. Sisyphus mexicanus. 20. Eurysternus angustulus, 21. E. caribaeus, 22. E. foedus, 23. E. magnus, 24. E. mexicanus. 

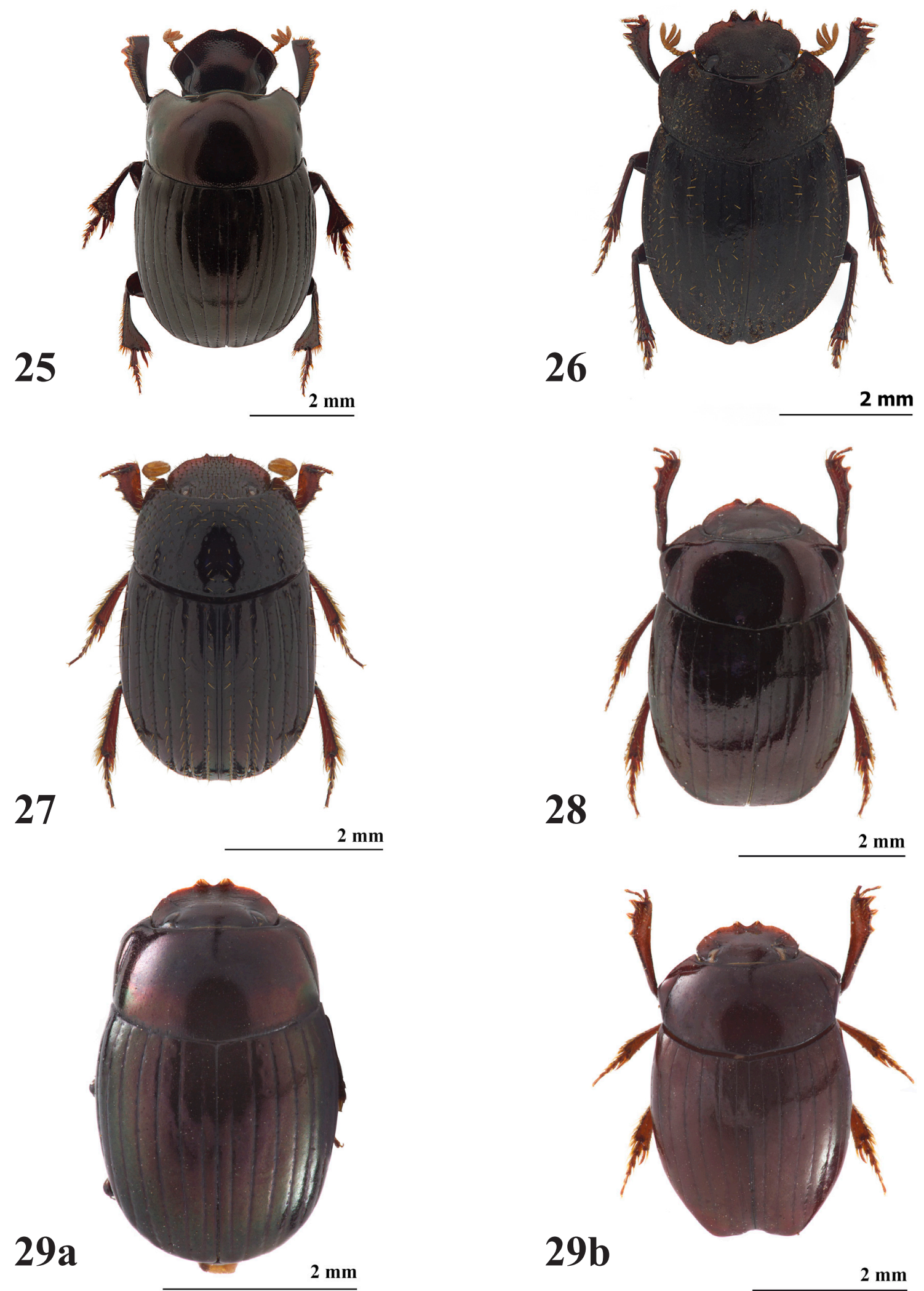

Figuras 25-29b. 25. Ateuchus chrysopyge, 26. Bdelyropsis bowditchi, 27. Martinezidium maya, 28. Uroxys chichanich, 29. Uroxys deavilai 29a + y 29b $\hat{\jmath}$. 

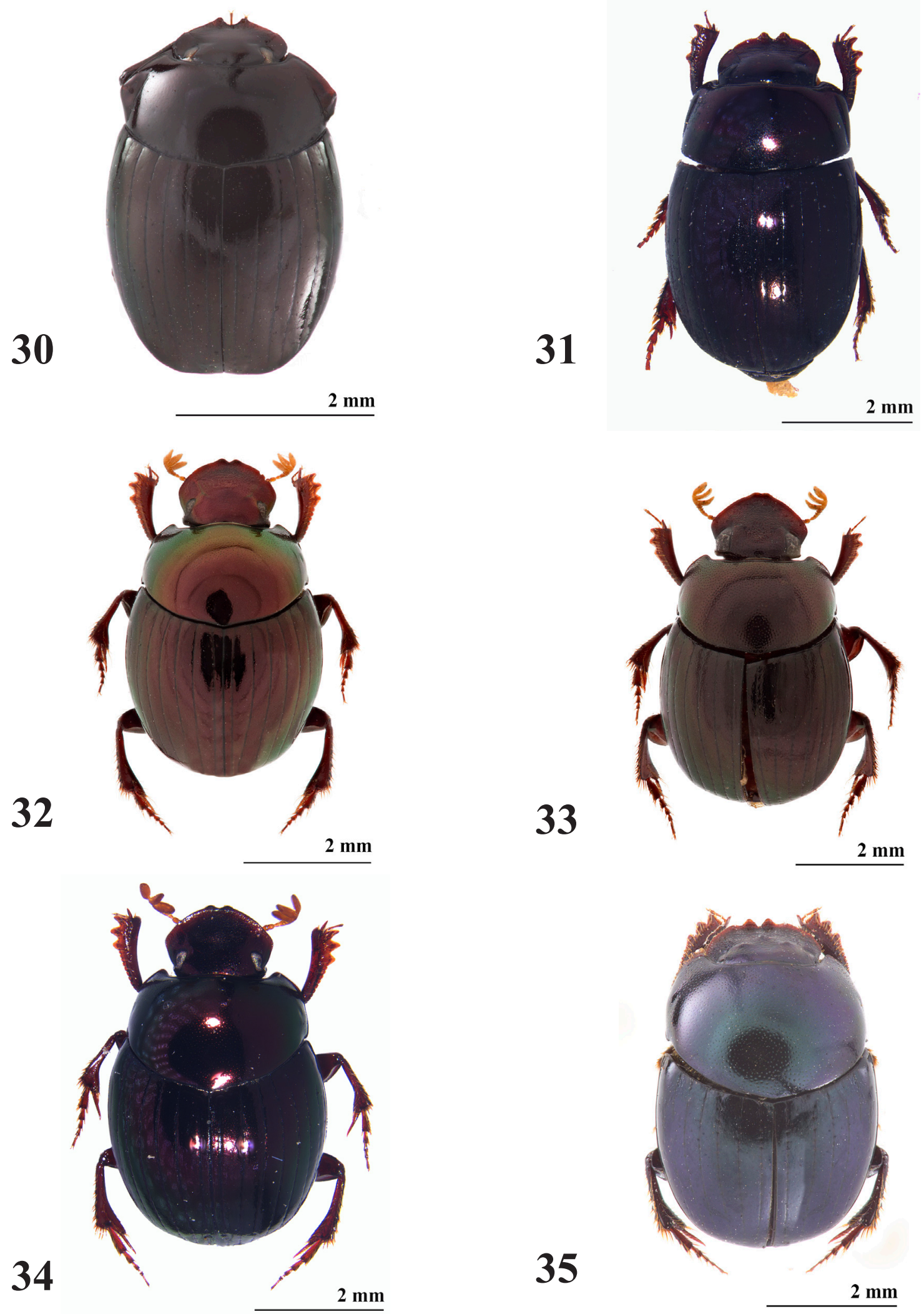

Figuras 30-35. 30. Uroxys microcularis, 31. Uroxys micros. 32. Canthidium (Canthidium) ardens, 33. C. (C.) moroni, 34. C. (C.) pseudoperceptible, 35. C. (C.) pseudopuncticolle. 

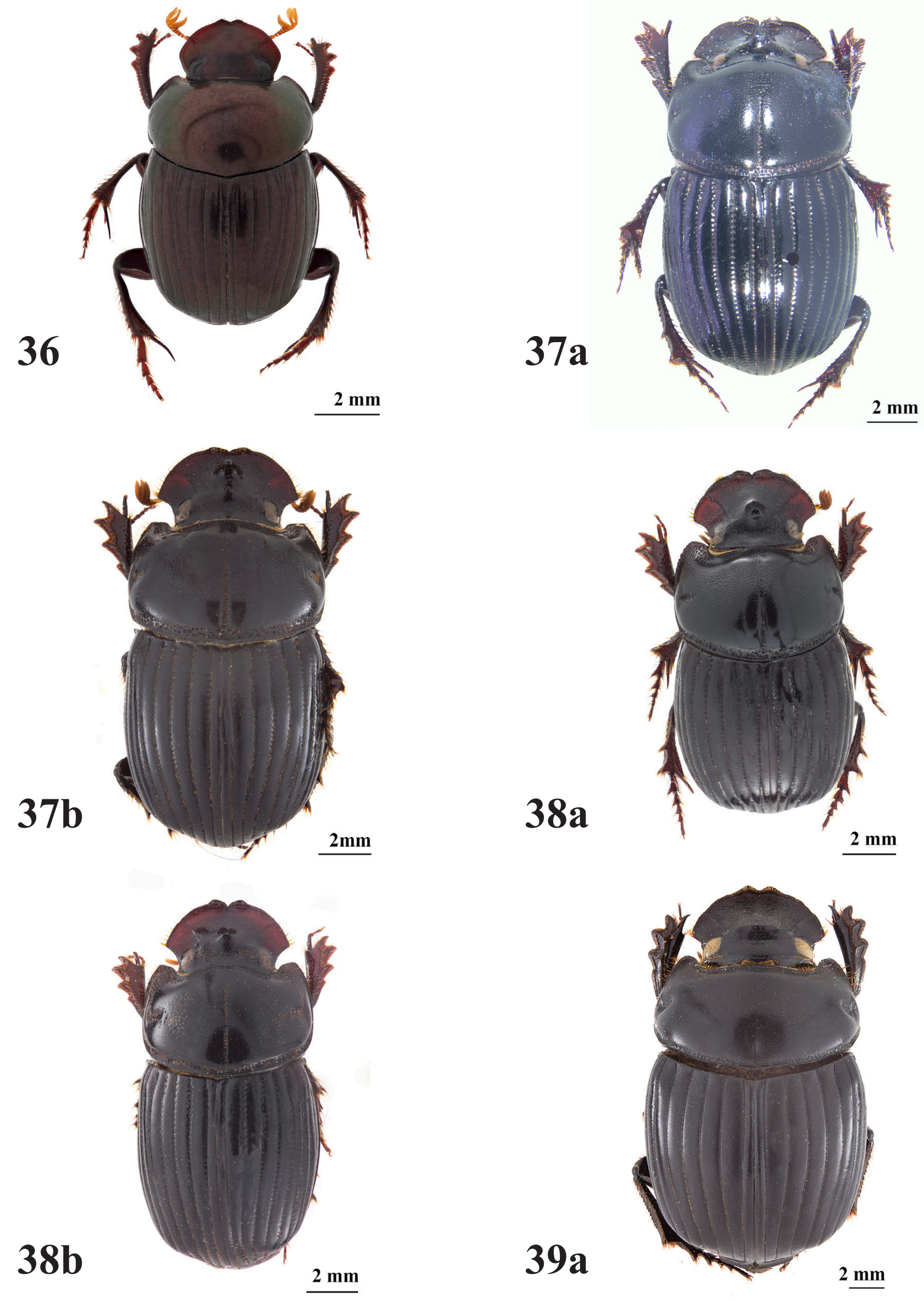

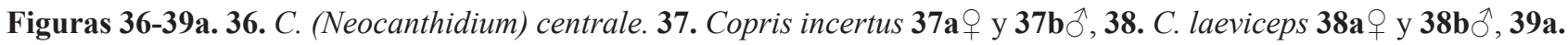
Dichotomius amplicollis +. 

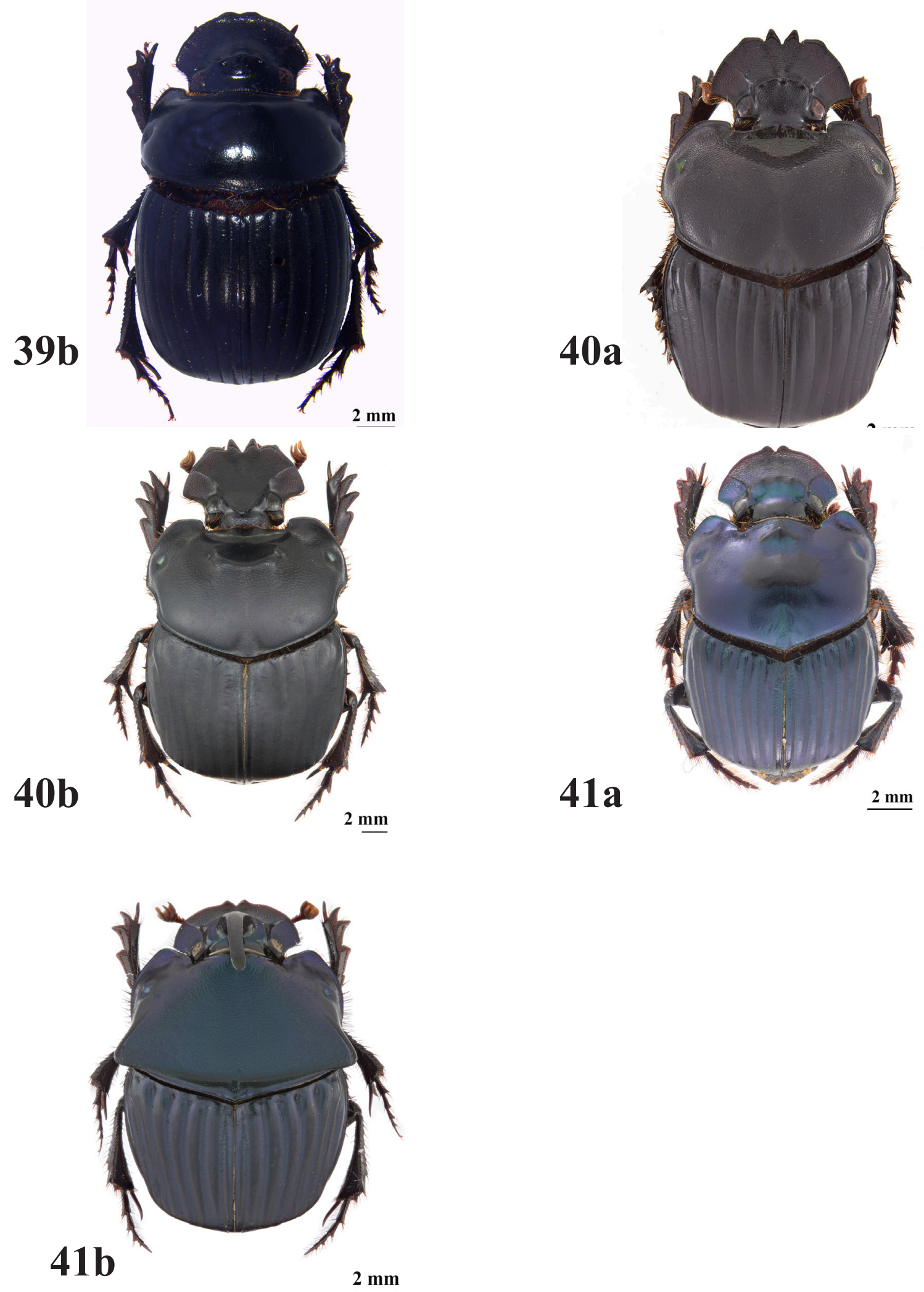

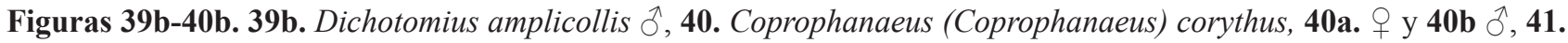
Phanaeus (Notiophanaeus) endymion 41a + y $41 \mathbf{b}{ }^{\lambda}$. 

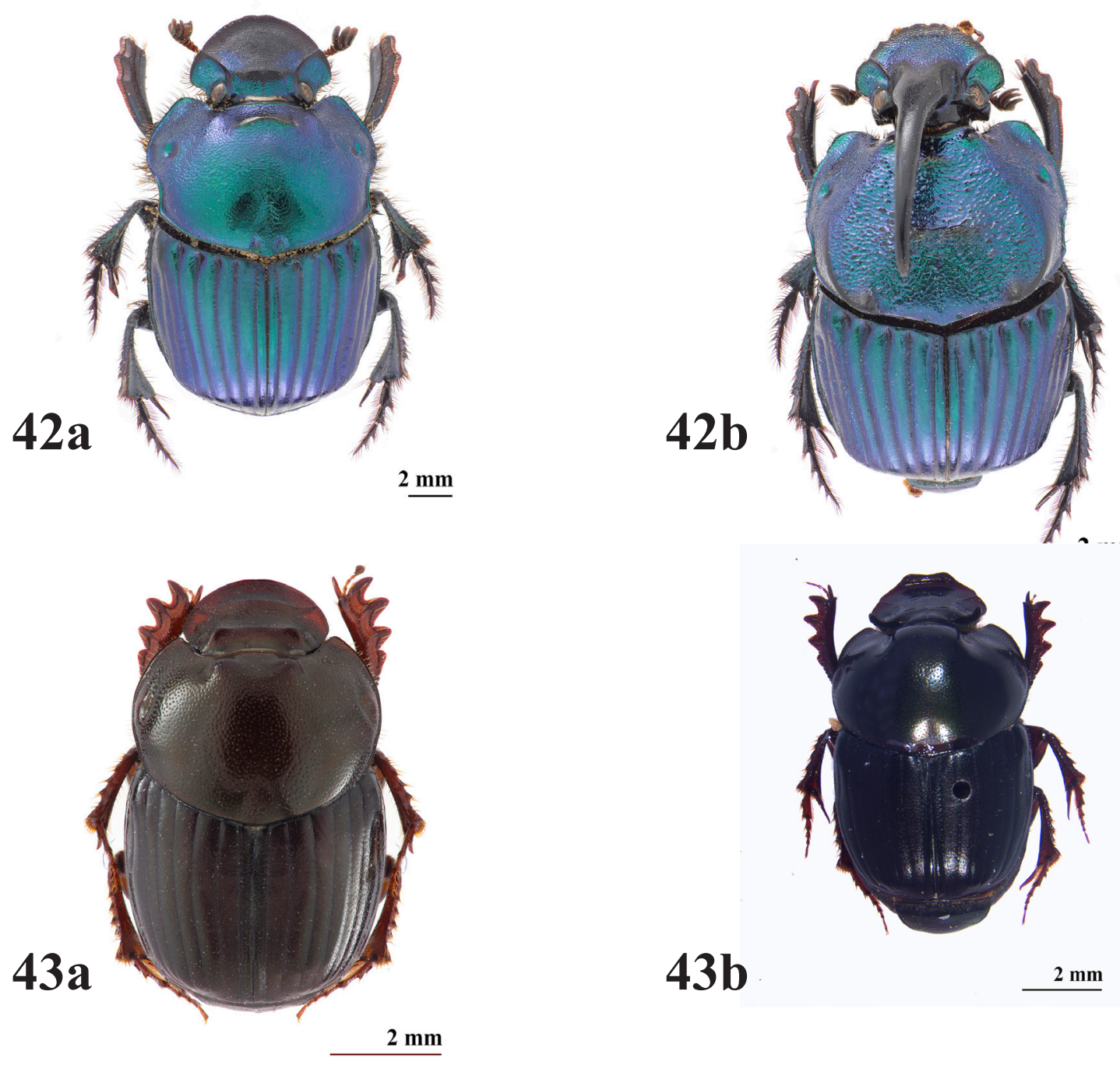

$43 b$
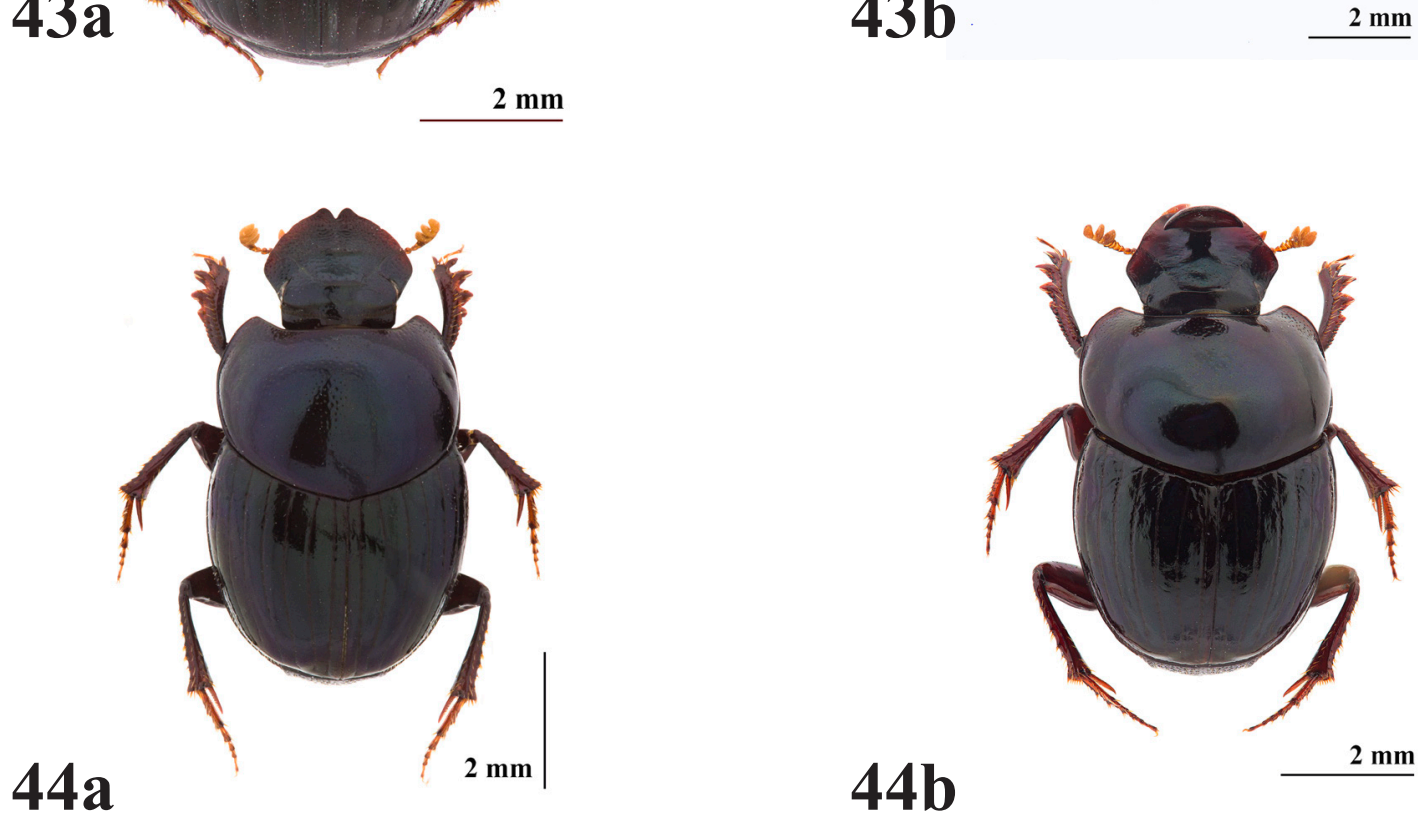

$44 b$

$2 \mathrm{~mm}$

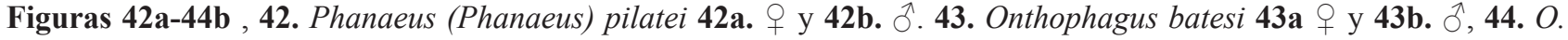
carpophilus $\mathbf{4 4 a}+$ y $44 \mathbf{b} \widehat{\overbrace{}}$. 

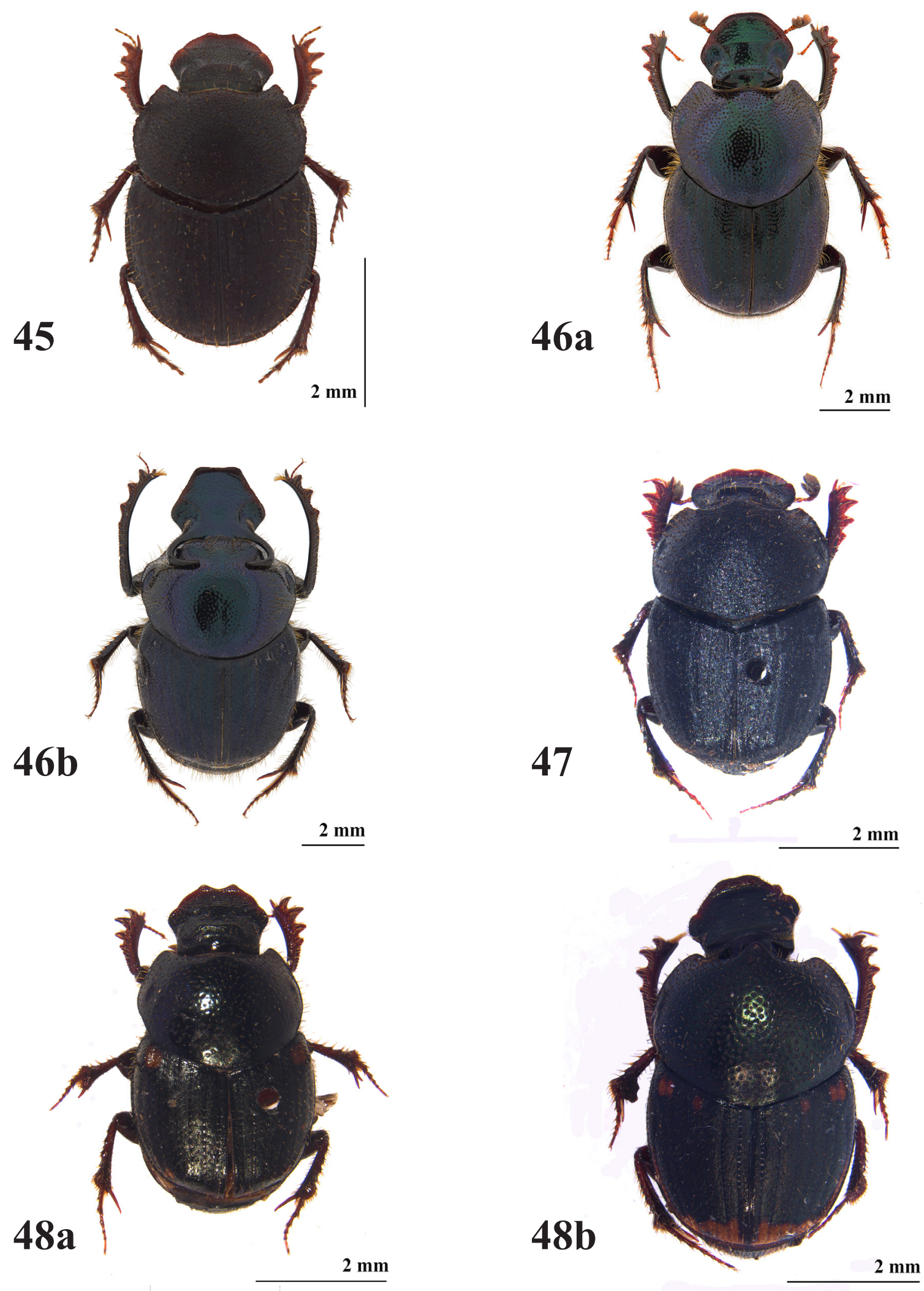

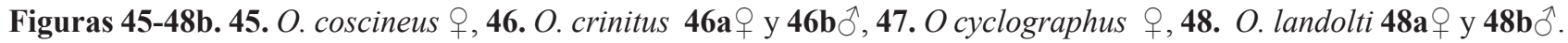



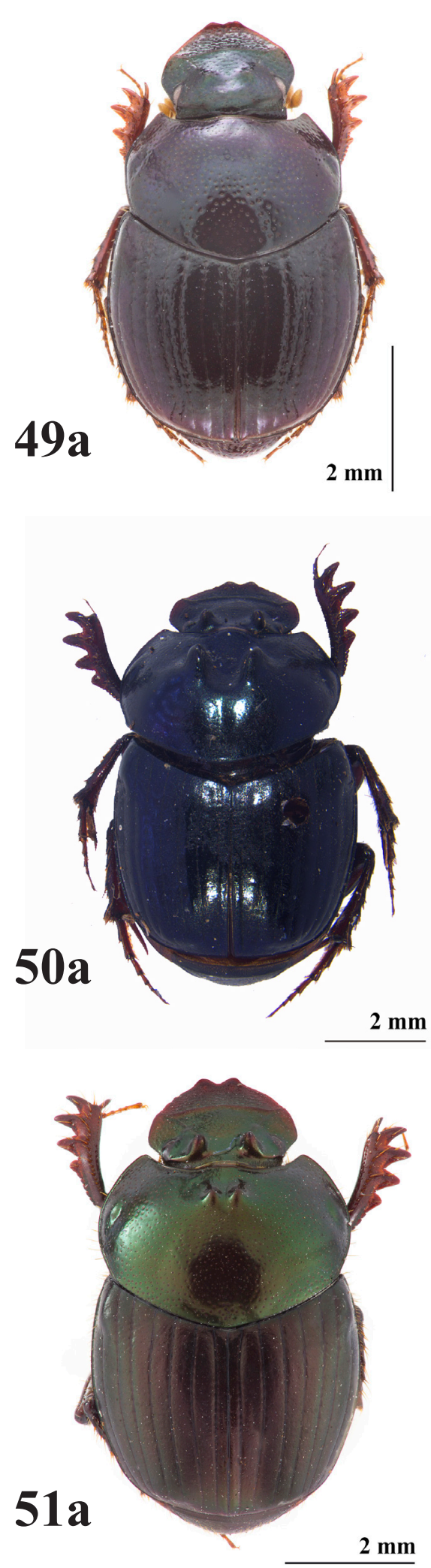
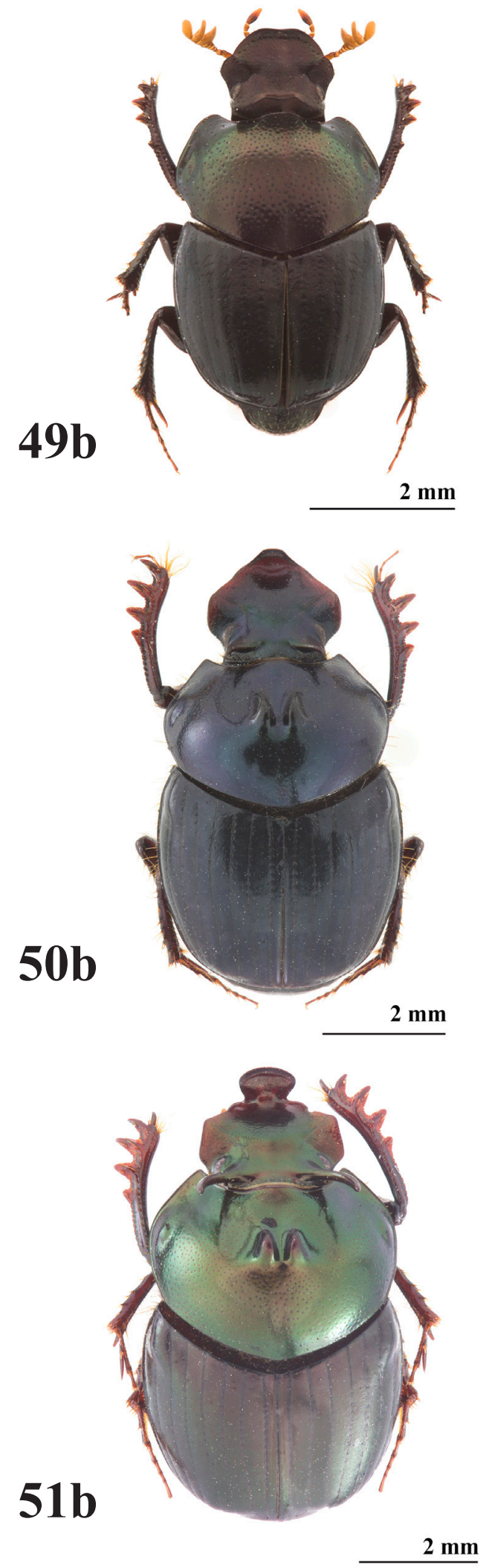

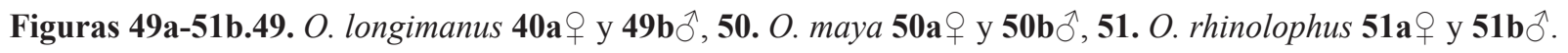



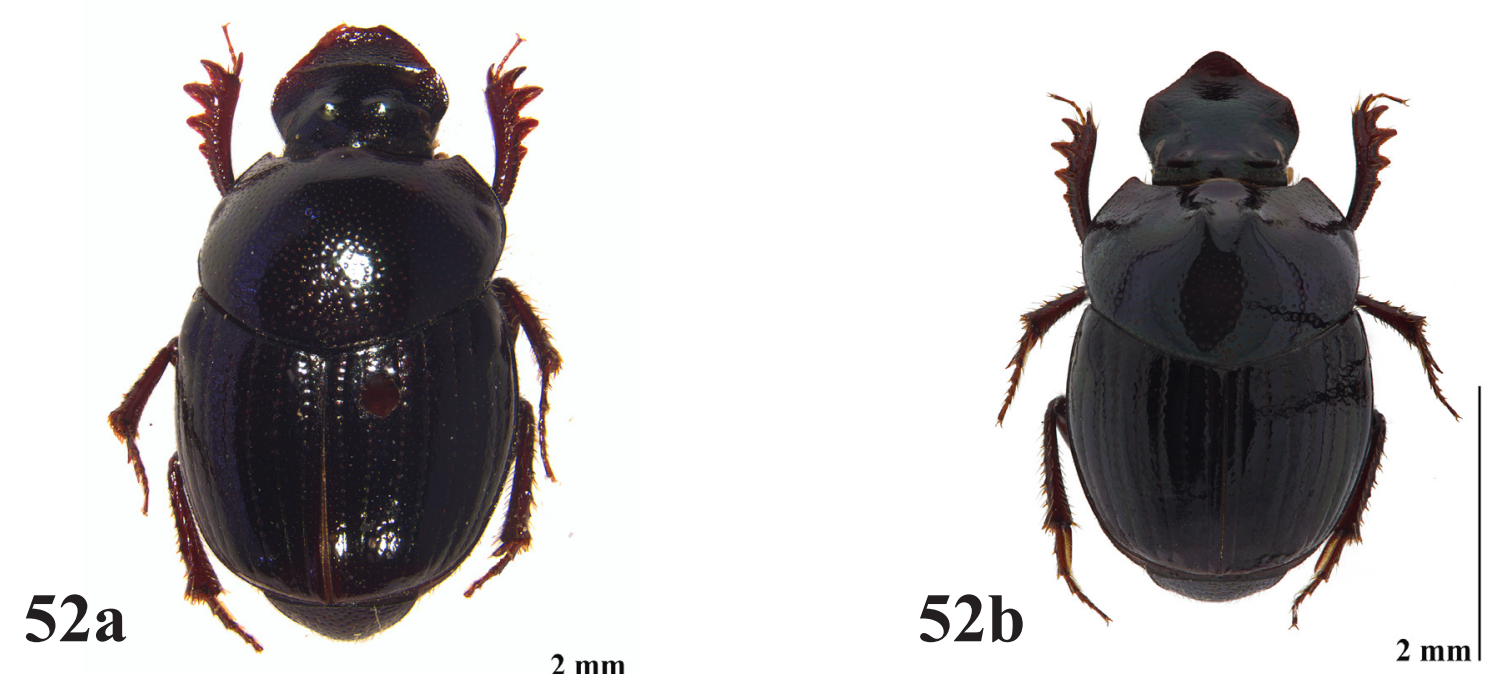

$2 \mathrm{~mm}$

Figura 52. Onthophagus yucatanus 52a 